\title{
DIVERSAS MANIFESTACIONES DE RIESGO SOCIAL Y MORAL DEL MENOR EN EL ÁMBITO DE TÉCNICAS DE INFORMACIÓN Y COMUNICACIÓN (TIC)
}

\author{
MARÍA VICTORIA GARCÍA-ATANCE \\ GARCÍA DE MORA
}




\section{SUMARIO}

INTRODUCCIÓN. I. PRINCIPIOS DE PREVALENCIA DEL INTERÉS SUPERIOR DEL MENOR EN LAS REDES SOCIALES. II. UNA REFLEXIÓN SOBRE LA INSUFICIENCIA DE LOS MECANISMOS JURÍDICOS EN TORNO A LA PROTECCIÓN DEL MENOR EN EL ÁMBITO DE LAS REDES SOCIALES. III. MEDIDAS PREVENTIVAS FRENTE AL RIESGO DE LOS MENORES EN LAS TICS E INTERNET. 1. Consentimiento. 1.1. Obtención del consentimiento. 2. Verificación de la edad del menor. 2.1. Limitación de edad mínima de participación en redes sociales. 3. Rastro de información de los Menores en las redes sociales. 4. Breve reflexión en materia de protección de datos de los Menores en la red. 4.1. Legislación aplicable. 4.1.a) Ámbito de la organización que utiliza los datos. 4.1.b) Ubicación de los sujetos cuyos datos han sido utilizados. 4.1.c) Ubicación del procesamiento real de los datos. 5. Proyección de riesgos sobre los derechos de la personalidad del menor: Regulación unitaria de la UE. 6. Influencia de la red en centros educativos: Su impacto emocional en menores. IV. PLANES EDUCATIVOS DE PROTECCIÓN EN LA CONVIVENCIA DEL MENOR Y REDES SOCIALES EN CENTROS EDUCATIVOS. POSICIÓN DE LOS TRIBUNALES SOBRE LA RESPONSABILIDAD DE LOS CENTROS EDUCATIVOS. V. APROXIMACIÓN CONCEPTUAL A DIVERSAS MANIFESTACIONES DE RIESGO SOCIAL DEL MENOR. 1. El menor ante episodios de acoso como factor de riesgo físico y social. 2. La vulnerabilidad del menor frente al ciberacoso: Factor de riesgo emocional. 2.1. Concepto. 2.2. Contenido. 2.3. Objetivos del ciberacosador. 3. Marginación del menor por maltrato escolar (Bullying): Factor de riesgo físico. 3.1. Concepto del Bullying. 3.2. Contenido de la figura del Bullying. 3.3. Objetivo de la agresión por Bullying. 4. El Ciberbullying como variante del ciberacoso. 4.1. Concepto del Ciberbullying. 4.2. Contenido del Ciberbullying. 4.3. Manifestaciones de Ciberbullying. 5. Diversas manifestaciones de riesgo social y moral del menor: Grooming como manifestación de maltrato y abuso en la indemnidad del Menor. 5.1. Objetivo del Grooming. 5.2. Secuelas Psicológicas del Grooming en el menor. 6. El Sexting como factor de riesgo telemático. 7 Morphing (Warping). VI. PROGRAMA TRANSVERSAL ANTE SITUACIONES DE RIESGO SOCIAL Y MORAL DEL MENOR. 1. Métodos de prevención ante el factor de riesgo. 2. Medios instrumentales de prevención. 3. Intervención. VII. LOS DERECHOS DE LA PERSONALIDAD Y LAS TIC COMO ELEMENTO TRANSGRESOR DE LA DIGNIDAD DEL MENOR. 1. Marco normativo de la dignidad e integridad del menor. 2. Las TIC y la Dignidad e integridad de la juventud y adolescencia. 3. Las TIC y los derechos de la personalidad. 3.1. Redes sociales y Derecho al Honor. 2.2. Redes sociales y Derecho a la Intimidad. 2.3. Redes sociales y Derecho a la propia Imagen. VIII. LA DOBLE VICTIMIZACIÓN DEL MENOR. CONCLUSIONES. 


\title{
DIVERSAS MANIFESTACIONES DE RIESGO SOCIAL Y MORAL DEL MENOR EN EL ÁMBITO DE TÉCNICAS DE INFORMACIÓN Y COMUNICACIÓN (TIC)
}

\author{
MARÍA VICTORIA GARCÍA-ATANCE \\ GARCÍA DE MORA*
}

\section{INTRODUCCIÓN}

La globalización y el recurso a las nuevas tecnologías de la información y comunicación, unidos al uso masivo de éstas por la infancia y adolescencia, representan una nueva circunstancia en la sociedad de la información de evidente relevancia social y jurídica, como afirma Cuerda Arnau ${ }^{1}$, pues al potencial de utilidad en el ámbito de la educación, información y cultura que aquél encierra, hay que sumar los riesgos que derivan de su inadecuado uso. Todo ello unido a la falta de vigilancia en este espacio junto al atractivo que tiene en ese segmento de tan temprana edad, aconseja estudiar la repercusión y peligros que tiene para el desarrollo y eventual vulneración de los derechos del menor.

Es conveniente diferenciar en Internet la web 1.0 que respondería a los inicios de la red, caracterizada, como señala Davara Fernández Marcos ${ }^{2}$ como web estática, basada en el texto y que proyecta la forma más simple que adoptó Internet en sus principios, de mera conexión de las personas a la web para consultar páginas y obtener información muy limitada. Sin embargo, a comienzos del siglo XXI se constata un paso actitud en los usuarios de una web estática a una web dinámica, web 2.0 caracterizada por la interactuación de los propios internautas a través de un intercambio de archivos e información y que permite poner en contacto a dos personas en puntos opuestos de globo.

\footnotetext{
* Profesora Titular de Derecho Constitucional, Departamento de Derecho Constitucional, Facultad de Derecho de la Universidad Nacional de Educación a Distancia, Obispo Trejo, 2, 28040 Madrid. Email: mgarcia-atance@der.uned.es

1 Cuerda Arnau, L. (2017), "Del Ciberbullying a la radicalización a través de Internet", en Menores y redes sociales. Coord. Fernández Hernández, A., Tirant lo Blanch, Valencia, pág. 17.

2 Davara Fernández Marcos, L. y E. (2017): "Delitos en redes sociales", en Delitos informáticos, Coord. Davara Rodríguez, M. A., Thomson Reuters Aranzadi, Pamplona, pág. 148.
} 
Este tipo de red 2.0 de última generación sería la protagonista de las redes sociales y blogs, en tanto que posibilitan el ágil intercambio de información en el que los usuarios juegan un papel activo.

De manera general cabe cifrar las características de la web 2.0 en las siguientes:

-El uso de la web como plataforma, y por tanto, aplicable no sólo a través de ordenador, sino mediante los dispositivos móviles al uso: smartphones, tablets, etc.

-Co-autoría en la red, ya que el usuario adopta papel activo en ella, colaborando con sus opiniones y sugerencias al enriquecimiento de ella.

-Agilidad en el intercambio de información a través de un soporte tecnológico que lo permita, por lo que la web 2.0 está en permanente transformación, conforme a sus necesidades, en versión beta perpetua.

-Común parámetro de búsqueda de información reconocible por los usuarios, dada la ingente cantidad de datos existente y casi inabarcable sin la existencia de un etiquetado clasificado en función del interés de la información de cada usuario.

-La web 2.0 proyecta su principal característica en que refleja su uso en comunidad frente a lo que sucedía con la web 1.0, de uso estrictamente individualizado, lo que se traduce en poder recabar información, publicar, opinar una permanente interacción entre los usuarios que configura en gran medida su éxito, pero tambien sus riesgos para el segmento más vulnerable de la sociedad: Los menores.

Es sabido que el ser humano necesita relacionarse socialmente, y este proceso se prolonga a lo largo de toda la vida, desde el momento inicial de su socialización, es decir desde pequeño, hasta alcanzar su grado máximo de sociabilidad. Cada vez más y con más frecuencia, los menores tienen a su alcance dispositivos tecnológicos a través de los cuales pueden relacionarse con poca seguridad y garantías entre ellos mismos.y con ello, muy fácil acceso a redes sociales, lo que provoca en ocasiones, buen número de riesgos, si no se aplica algún control sobre verificación edad, identidad, etc.

En este escenario, es fácil deducir que una etapa crucial del proceso, se sitúa en la fase escolar, propia de la infancia y adolescencia. El sistema educativo de la sociedad del Siglo XXI, ha diseñado un plan de estudios para formar a las niñas y niños en la excelencia académica tanto en un área científica, técnica, humanística y artística, lo que responde a un esquema formativo idóneo, pero que sin embargo, choca con el creciente número de desencuentros de convivencia, ya desde muy temprana edad, en los diferentes centros escolares, así como el número de depresiones en este colectivo de infancia y adolescencia que aparecen en ambientes escolares.

En este orden, nos planteamos con Quicios García ${ }^{3}$ si los centros escolares atienden a ese sistema formativo mencionado, y por su parte las familias cubren las necesidades de los hijos, ¿Cuál puede ser el desencadenante de los riesgos socioemocionales y problemas psicosociales que se están desencadenando en la infancia y especialmente en la adolescencia? Y aún más, cabe plantearse la cuestión en torno a si la legislación que regula esta materia, dada la casuística que encierra y la rapidez con la que evoluciona la tecnología de las TICs, es suficiente para garantizar la protección de los derechos de los menores que con más frecuencia son vulnerados en este ámbito.

Una posible respuesta podría ser que un ámbito tan relevante como el socioeducativo, no se ha controlado lo suficiente, lo que ha generado que algunas peligrosas manifestaciones de riesgo social infantil, se estén proyectando con carácter general, en los Centros escolares en formas varias e igualmente atentatorias contra la libertad, dignidad e intimidad de los menores, a las que nos referiremos más adelante.

${ }^{3}$ Quicios García, P. y Moreno, R. (2012): "Riesgos emergentes en las relaciones entre niños: Acoso, ciberacoso, bullying, ciberbullying grooming" en Menores en crisis (coord. FERnÁndez TILVE y SuÁREZ SANDOMInGO), Universidad de Santiago de Compostela, pág. 518. 
Hay ciertas cuestiones de cierta trascendencia sobre las que nuestra sociedad reclama atención prioritaria y que acaban por convertirse en retos irrenunciables: La violencia, la escasa presencia de valores éticos, la discriminación y desigualdades que requieren planes de convivencia desde temprana edad, ya en la formación escolar, pues lo que está claro es que nuestra juventud necesita, más que nunca, pautas para convivir en sociedad y comprender la realidad social del mundo en el que viven, dentro de unas normas de respeto hacia los demás, es decir, en un marco de convivencia diaria en la escuela y en el ámbito familiar, saludable y estimulante, de afectos y actitudes positivas, como señala Fernández Tilve ${ }^{4}$, reforzando sus habilidades sociales y modificando sus tendencias antisociales.

En este contexto, se proyecta un gran caldo de cultivo para ciertas actividades provenientes del desarrollo de las tecnologías de la información y de la comunicación (TICS), especialmente Internet, que siendo una gran revolución para la humanidad, y aportándonos enormes beneficios, sin embargo, también muestra su lado oscuro, como instrumento idóneo para, amparándose en el anonimato, perpetrar actuaciones ilícitas, que cuando son empleadas particularmente por niños o adolescentes sin control, pueden generar graves consecuencias tanto para ellos mismos, como para los demás. Desde esta consideración, se hace obligada la formación de la juventud e infancia conforme a unas pautas para solucionar los problemas de convivencia, en definitiva, a través de los planes de convivencia.

\section{PRINCIPIOS CONFIGURADORES DE LA PREVALENCIA DEL INTERÉS SUPERIOR DEL MENOR EN LAS REDES SOCIALES.}

Se reconocen determinados principios esenciales establecidos en las directrices de la OCDE de 1980, o en el Convenio 108 del Consejo de Europa, así como en la Resolución 45/95 de la Asamblea General de las Naciones Unidas, Principios tales como legalidad, seguridad, transparencia, responsabilidad, calidad de datos en las redes sociales, que serían recogidos posteriormente en la Directiva 95/46/CEE y en nuestra Ley Orgánica de Protección de datos, lo que no excluye la existencia de otros, como señala Piñar Mañas ${ }^{5}$,como es la prevalencia del interés superior del menor.

Ya el Grupo de trabajo del artículo 29 en su documento 1/2008 WP 147, y en la Opinión 2/2009, ambos sobre la protección de datos de los niños, subraya su interés.

A partir de estos documentos, confirmados posteriormente por la Convención 192 del Consejo de Europa (artículo 6) y la Carta de los Derechos Fundamentales de la UE, (artículo 24), resalta la importancia del derecho a la privacidad de los menores, que incluye principios de protección de datos: calidad, finalidad, información, rectificación y oposición que se cifran en la intimidad de los menores.

De entre los documentos mencionados referentes a la protección de la privacidad del menor, ocupa lugar relevante la Opinión 5/2009 sobre redes sociales, en la que se recuerda que una gran parte de los usuarios de éstas, son menores, y el Dictamen WP 147 del Grupo de Trabajo, reconoce, que la protección del menor es

\footnotetext{
${ }^{4}$ Fernández Tilve, M.D. (2012), "El plan de convivencia en los centros escolares: una mirada reflexiva" en Menores en crisis (coord. FernÁndez Tilve y SuÁREZ SANDOMingo), Universidad de Santiago de Compostela, pág. 20.

5 PiÑAR MAÑAS, J.L. (2011):'El derecho fundamental a la protección de datos y la privacidad de los menores en las redes sociales", en AAVV (director PIÑAR MAÑAS), Redes sociales y privacidad del menor. Solventia, Editorial Reus, Madrid.
}

(C) UNED. Revista de Derecho Politico

N. 100 , septiembre-diciembre 2017, págs. 1271-1308 
particularmente relevante en este ámbito, instando en consecuencia a una estrategia pluridimensional, basada en diversas orientaciones como:

- Iniciativas de sensibilización para garantizar la protección de la intimidad del menor, con inclusión de elementos de protección de datos en centros escolares, así como colaboración de organismos nacionales competentes.

- Un tratamiento justo y legal sobre los menores, como, por ejemplo, no pedir datos sensibles del menor en determinados formularios sobre éste, ni tampoco, realizar comercialización directa, destinada específicamente a menores, y por otra parte, establecer grados de separación lógica entre las comunidades de menores y adultos..

- Instalación de tecnologías que mejoren la protección de la intimidad del menor, como ventanas emergentes de advertencia en fases adecuadas, así como programasinformáticos de verificación de la edad.

- Autorregulación de los proveedores al fin de fomentar la adopción de buenas prácticas que incluyen medidas de ejecución eficaces y sanciones disciplinarias.

- Medidas legislativas adecuadas para eludir prácticas fraudulentas en el contexto de las redes sociales

Todo ello conduce a una reflexión sobre la privacidad de la intimidad en este ámbito de redes sociales, en la pretensión de lograr un equilibrio entre ambos, en el que el papel del jurista se manifiesta imprescindible, debiendo hacer el derecho, frente al reto del avance tecnológico, particularmente en lo que afecta a la protección de la privacidad del menor en función de su interés superior ${ }^{6}$. En este sentido es importante tanto que el menor no pierda el control sobre la información que le afecta, o cuando menos, conocer los medios, medidas e instrumentos que puedan garantizarlos, ya que frecuentemente no cuentan con el consentimiento del otro menor para volcar su información en las redes, así como tambien es determinante, que los proveedores de redes sociales, asuman la responsabilidad de implantar medidas de seguridad adecuadas.

Desde esta reflexión es necesario, como afirma, Rodotá ${ }^{7}$, lograr un equilibrio entre el exceso prohibicionista y visión reduccionista derivada del control pluridireccional, frente al amplio espectro de oportunidades que ofertan las redes sociales, lo que requiere una acción preventiva y formativa, con una participación de todos, ,es en síntesis, como invoca el autor, la aplicación de un tratamiento sobre la privacidad del menor, conforme a aspectos relevantes según criterios de edad, madurez, formación etc, del menor que comportan una "desegregación" en su tratamiento, pero teniendo presente la idea central del desarrollo de la personalidad del menor, que implica, de un lado, su privacidad, y de otro lado, la libertad de expresión e información .

La idea pues es que las redes sociales e Internet, se proyecten como auténticos instrumentos de civilización, de nuevas posibilidades, de relaciones sociales de participación; equilibrio, en definitiva, en el que juristas, proveedores y usuarios de redes sociales, deben necesariamente concurrir.

\footnotetext{
${ }^{6}$ L. Orgánica 8/2015, de 22 Julio, de Modificación de la Ley Orgánica del sistema de Protección a la infancia y a la adolescencia.

7 RoDotÁ, S. (2011), “Sociedad contemporánea, privacidad del menor y redes sociales", en AAVV (director Piñar Mañas), Redes sociales y privacidad del menor. Solventia, Editorial Reus, Madrid, pags. 35 y ss. (C) UNED. Revista de Derecho Político 


\section{REFLEXIÓN SOBRE LA INSUFICIENCIA DE MECANISMOS JURÍDICOS EN TORNO A LA PROTECCIÓN DEL MENOR EN EL ÁMBITO DE LAS REDES SOCIALES.}

La comprobada afluencia de menores a Internet y redes sociales y desinhibida navegación por las mismas, ponen de manifiesto, como afirma Lucas Murillo ${ }^{8}$, el creciente riesgo de las tecnologías de la información y de la comunicación cuyo avance responde a una progresión geométrica frente al desarrollo jurídico para su regulación adecuad ; tal situación, avivada, de una parte por los emprendedores, quienes saben moverse a ese ritmo y que atisban el enorme potencial que tales novedades tecnológicas ofrecen, así como de la gran utilidad de sus servicios aunque no vayan dotados de salvaguarda de prevención ante eventuales riesgos, y de otra parte por la predisposición de los menores abiertos a los nuevos instrumentos de su generación tecnológica, plantean una urgente reflexión en torno a la suficiencia o no de remedios que nuestro ordenamiento jurídico-constitucional ofrece.

La respuesta ha de ser afirmativa, en términos generales, ya que el ordenamiento ofrece medios para proteger a los menores de los peligros que acechan en sus comunicaciones electrónicas y redes de comunicación.

No obstante, como en todo ámbito, siempre se es susceptible de mejorar las normas, instituciones, Defensor del menor eficaz y procedimientos existentes, si bien, para lograr el máximo beneficio de la normativa existente en el ordenamiento jurídico actual, es preciso igualmente asegurar otras áreas orientadas a la protección del menor, pero diferentes a la estricta concreción normativa, proyectando esta inquietud a la difusión de la concienciación del problema la sociedad, padres e hijos, así como educadores y transmitirlo también, como afirma Lucas Murillo', a quienes tienen responsabilidades políticas, económicas y sociales, para que proyecten en su ámbito de actuación, criterios respetuosos en torno al menor, y en este sentido, no sería desdeñable, la existencia de un instrumento, a modo de estatuto particular, específicamente orientado a las limitaciones que en esta materia deban existir, para quienes llevan actividades dirigidas al público en general y a los menores en particular, para reducir los riesgos existentes, obligándoles a tomar medidas y previsiones específicas, dirigidas a contrarrestar tales peligros.

En esta línea, no bastaría con fomentar determinadas prácticas, sino desarrollar algunas reglas singulares que materializaran esa medida de protección, revistiendo carácter obligatorio, tales como:

-Edad de los menores para el acceso a determinados instrumentos de tecnología de última generación.

-Obligación de suministrar, con los aparatos y programas que permiten el acceso a Internet o redes, filtros y mecanismos que permitan a quienes tengan menores bajo su responsabilidad, la posibilidad de limitar la navegación de éstos por la red, en determinados supuestos, y no sólo desde su ordenador personal, sino que de igual modo, limiten el acceso de los menores desde terminales de lugares públicos - La responsabilidad y obligación por parte de quienes gestionan las redes sociales, de dotarse de sistemas de verificación de la edad de quienes se integran en ellas, y en todo caso, de activación de limitaciones tan pronto como se detecte que un usuario puede ser menor de edad.

\footnotetext{
${ }^{8}$ LuCAs Murillo, P. (2011): “Observaciones sobre la privacidad del menor ante las nuevas tecnologías, instrumentos jurídicos y competencia judicial”, en AAVV (director Piñar Mañas), Redes sociales y privacidad del menor. Solventia, Editorial Reus, Madrid, págs. 109 y ss.

${ }^{9}$ LuCAs Murillo, P. (2011), Ibidem.
}

(C) UNED. Revista de Derecho Politico

N. 100 , septiembre-diciembre 2017, págs. 1271-1308 
Todo ello va así dirigido a lograr una disminución efectiva de los riesgos que circulan respecto a los menores en la red.

\section{MEDIDAS PREVENTIVAS FRENTE AL RIESGO DE DEL MENOR EN LAS TICS}

\section{Consentimiento.}

Uno de los problemas que se plantean en torno a la protección del menor frente a las redes sociales, es el que deriva del consentimiento como título habilitante para el tratamiento legítimo de los datos, si bien, no siempre es así.

Hay supuestos en que la ley permite tratar datos, aún en contra del consentimiento de los interesados (artículos 6 y 11 de la LOPD).

El consentimiento de los menores es particularmente sensible. Conforme al artículo 13, apartado 1, del RLOPD, se pueden tratar los datos de los mayores de 14 con su consentimiento, si bien esta normativa tras la LO 8/ 2015 de 22 de julio de protección de infancia y adolescencia, admite el consentimiento del adolescente maduro de 12 años..

Uno de los problemas que genera más complejidad es el de la acreditación de la obtención del consentimiento, sobre todo a través de Internet, en el que no existe relación directa con los afectados. Por ejemplo, la AEPD parece haber llegado a un acuerdo con Tuenti, para que ésta pueda solicitar el DNI a los usuarios de quienes se sospecha que su edad es inferior a 14 años.

A pesar de ello, la realidad refleja que estas cautelas son mayoritariamente ineficaces, de un lado por la indiferencia que muestran las redes sociales en torno a estas medidas preventivas para la protección del menor, y de otro lado, por lo que supondría un esfuerzo extraordinario por parte de los proveedores de aquéllas, de verificar y confirmar la edad del menor, como pone de relieve Piñar Mañas ${ }^{10}$.

Por otra parte, las redes sociales son proclives a volcar infinidad de datos personales de terceros frecuentemente sin su consentimiento .En este sentido, el Grupo de trabajo del artículo 29, ha reiterado en la Opinión 5/2009 que los proveedores de las redes sociales, deben recordar a sus usuarios que la utilización de datos de terceras personas, así como fotografías sin consentimiento, pueden vulnerar su intimidad .Tales serían igualmente los supuestos de datos volcados por parte de los menores, indirectamente sobre sus propios padres, al subir datos personales suyos, o el supuesto de transferir a terceros información personal sobre otros menores, que deben estar sujetos a consentimiento explícito de sus padres o representante legal.

El consentimiento en las redes sociales ha sido objeto de inquietud en el Grupo de trabajo, que ha cristalizado en Dictámenes sobre la materia mencionada, señalando que un gran número de redes sociales son utilizadas por menores y en relación con dichas redes ha implementado los principios subrayados en el Documento $n^{\circ} 1 / 2008$, particularmente centrado en los principios de protección de datos en entorno escolar y educativo. En todo caso hay que señalar que el consentimiento de los progenitores para el procesamiento de datos sobre el menor, está limitado en el tiempo hasta que llegue a estar capacitado para tomar sus propias decisiones, conforme define el artículo 162.1del Cc, al referirse al menor no emancipado, pero que puede realizar por sí mismo, actos relativos a los derechos de la personalidad, cuando cuente con madurez para ello, cifrandose esta edad para actuar por sí mismo en esta materia, en 14 años .

10 PiÑAR MAÑAS, J.L. (2011): “El derecho fundamental...”, ob. cit. 


\subsection{Obtención del consentimiento}

Las normas de privacidad pueden ser simplemente mencionadas en las condiciones de uso de un sitio web, pero, aún así, existe una gran dificultad en forzar a los menores a leer las normas de privacidad, siendo un escaso $6 \%$ el porcentaje de ellos que lo siguen, frente a lo que acontece en otros países cuyos ordenamientos se muestran más proclives a regular el consentimiento en materia de protección de información personal, como el caso de la Ley de información personal, protección y documentos electrónicos (PIPEDA), cuyo Anexo 1 (Principio 3, 4.3.1.), exige que el consentimiento debe obtenerse a fin de utilizar, recopilar o divulgar información personal, lo que se justifica con más motivo en caso de menores.

Entre las diversas vías que en el anexo 1 de dicha ley se enumeran para la obtención del consentimiento, se define que el usuario otorga su consentimiento a través de la firma del formulario, quedando implícitamente reconocido que de no firmarlo, la persona autoriza la transferencia de su información a terceros.

\section{Verificación de la edad del menor ante las redes}

Los retos planteados en torno a la verificación de la edad de los menores usuarios, suscita gran dificultad al constituir una cuestión de alto nivel técnico e informático, de tal entidad que los reguladores han solicitado a los proveedores de servicios, que verifiquen la edad de los miembros de las redes sociales, sin efectuar una propuesta concreta.

La cuestión de la verificación de la edad e identidad en menores encierra la dificultad añadida de que habitualmente éstos no disponen de tarjetas de crédito, o permiso de conducir, u otros elementos de información útiles a este efecto, pero además existen leyes, como afirma Benyekhlef ${ }^{11}$, que en materia de privacidad regulan el mantenimiento de este tipo de información, lejos del público.

\subsection{Limitación de edad minima de participación en redes sociales.}

Conforme a las Directivas de la UE, no existen normas concretas que establezcan cómo pueden consentir los menores respecto a datos que les atañen, considerando estos asuntos que pueden configurar materia objeto de interpretación por la ley nacional, estando normalmente vinculados a la capacidad de contratar, considerando ésta una edad de cierto vivel de madurez, y por tanto queda definida conforme a las leyes de los estados miembros.

Las normas referentes al límite de edad para usuarios de redes sociales estan actualmente en revisión. El 10 de Febrero de 2009, varios miembros de la UE formalizaron un acuerdo con 17 redes sociales, a fin de incrementar la seguridad de los menores.

Algunas redes sociales han establecido un límite de edad que, por ejemplo, Facebook, cifra en 14 años, pero cuya página web no informa no informa abiertamente de ello, porque seguramente intuye que si los menores conocen tal límite, seguramente ocultarían su edad real.

La fijación de los 14 años como barrera en minoría de edad a estos efectos, viene avalada por el artículo 13 del Real Decreto 1720/2007 de 21 Diciembre por el

11 BenyeKhlef, K. (2011), "Menores, redes sociales y derecho al olvido" en AA.VV. (director Piñar Mañas), Redes sociales y privacidad del menor. Solventia, Editorial Reus, Madrid.

(C) UNED. Revista de Derecho Politico

N. 100 , septiembre-diciembre 2017, págs. 1271-1308 
que se aprueba el Reglamento de desarrollo de la Ley Orgánica 15/1999 de 13 de Diciembre de protección de datos de carácter personal que fija la edad de 14 años.Esta prescripción viene atemperada, en todo caso, como advierte Villanueva Turnes ${ }^{12}$ por la previsión de la Agencia Española de protección de datos, al señalar que "Para el supuesto de mayores de 14 años cuya madurez no garantice la debida comprensión del consentimiento prestado, el consentimiento de sus representantes legales.

\section{Rastro de información de los menores en las redes.}

Lo referido hasta ahora en relación a la autorización del menor en redes sociales, divulgación de datos personales y consentimiento, así como edad mínima para la participación en redes, abona aún más un nuevo problema que surge en este ámbito consistente en que, como es frecuente que los menores adolescentes suelen subir información personal sobre ellos mismos, muchos de estos datos volcados terminan estando en línea, como con acierto afirma Benyekhlef ${ }^{13}$, que pueden ser fácilmente almacenados, copiados y circular de nuevo, perdiendo los originarios propietarios el control sobre éstos, lo que abre una cuestión en torno a si la voluntariedad de la información divulgada en un momento determinado, comporta la pérdida absoluta del control sobre tal información de manera permanente, hurtando la capacidad del cuando y cuánto puede mantener Internet tal información.

En la medida que la juventud va asumiendo un papel más activo en la sociedad de la información, va dejando atrás un importante rastro de datos registrados y almacenados en servidores de todo el mundo, así, Facebook, conserva las fotografías de todos los usuarios, y las distribuye a continuación a sus servidores, así como cualquier otra interacción efectuada por los usuarios: fotografías, mensajes, perfiles, etc; ya que Facebook incrementa sus ingresos con la interacción de los usuarios. Esto permite que la información aportada por el menor, quede cautiva, y por tanto, susceptible de ser manipulada o utilizada con fines distintos al fin previsto, en una perennidad de la información excluyente de la autodeterminación informativa del menor como señala Burguera Ameave $e^{14}$.

Todo ello conduce a concluir que en la cultura digital actual, la tecnología proyecta un papel determinista, en tanto que conforma, modifica y altera la forma en que vivimos, provocando un impacto directo en nuestra convivencia social y en este orden, la erosión de nuestra privacidad, es un reto con el que ha de convivir nuestra sociedad. En este contexto, la pretensión de proteger la privacidad de los menores adquiere un relieve de primera magnitud, ya que su generación decidirá sobre el patrón del posterior desarrollo de las tecnologías en materia de protección de sus derechos.

\section{Breve reflexión en materia de protección de datos de los menores en la red}

Conforme al artículo 6.1b) de la Directiva 95/46/CE, los datos recopilados de menores no pueden ser utilizados para fines diferentes a aquéllos que justifican su recopilación.

Sin embargo, son muy frecuentes los casos en los que se infringe tal norma, como en los casos de centros docentes o escuelas, o de los operadores de sitios web

\footnotetext{
12 VillanueVA TuRnes A. (2017), "El derecho a la intimidad y el consentimiento de los menores de edad", en Revista Boliv. de Derecho no 23 Enero 2017.

13 BenYEKHLEF, K. (2011): "Menores, redes sociales ....", ob. cit.

14 Burguera Ameave, L. (2013): “Autodeterminación Informativa”, AA.VV., Menores e internet, Thomson Reuters Aranzadi, Navarra. 
que proporcionan datos de nombres y direcciones de menores a terceros, por ejemplo en supuestos comerciales y que quieren contar con menores como clientes.

El mencionado artículo 6 de la Directiva 95/46/CE determina que sólo podrán ser recogidos datos adecuados, relevantes y no excesivos. A tal efecto, es particularmente prioritario notificar a los menores sobre los posibles riesgos y peligros que se derivan de las actividades en línea, como afirma algún sector de la doctrina representado por Buttarelli $^{15}$, debiendo ser presentadas estas notificaciones informativas en el momento y lugar adecuados, como, por ejemplo, en la propia pantalla y antes de recibir la información que afecta al menor.

En este sentido, el Grupo de Trabajo del artículo 29 insta a la conveniencia e incluso necesidad de que los centros escolares y los padres, establezcan las medidas necesarias para orientar a los menores en sus responsabilidades, enfatizando la necesidad de fomentar la formación de los menores en la cultura del uso de las nuevas tecnologías, a una edad lo más temprana posible, en relación al respeto de la privacidad, así como sobre el uso de la información que afecta a otros menores, informándoles de la existencia de normas legales en este contexto, así como de los peligros asociados con la publicación y visibilización de datos personales, tanto propios, como ajenos, en atención a la amplia difusión de la información que se suministra al subirla a la red.

Desde la óptica de datos utilizados sin consentimiento alguno, es reseñable la aportación de las actividades del mencionado Grupo de Trabajo, orientado a la aplicación de los principios de la recopilación de datos de menores, y, aún así, no del todo suficiente, requiriéndose cara a un futuro mediato, la implantación de mayores garantías en torno a los menores, como decíamos con anterioridad, respecto al control de la edad de los menores en las redes, el consentimiento en la recogida de datos, y especialmente, como afirma Buttarelli ${ }^{16}$, en el margen de mejora en la forma en que se aplican las directivas en la recopilación de información personal de los menores en la sociedad de la información.

\subsection{Legislación aplicable}

En estrecha imbricación con el problema de la protección de los menores en la red, se sitúa la cuestión de la legislación aplicable, particularmente en los supuestos de delitos en la red, a los que nos referimos en otro epígrafe del trabajo.

El criterio general de la aplicación de las leyes es el del establecimiento del responsable del tratamiento de los datos, lo que significa que la nacionalidad y lugar de residencia habitual del sujeto de los datos, es irrelevante, lo que redunda en posibles aplicaciones extraterritoriales.

La Directiva 95/46 y las leyes nacionales que la incorporan, se aplican al procesamiento de datos personales fuera de la UE, así como a los responsables establecidos fuera de la UE.

Existen tres planteamientos distintos con carácter general para definir la aplicación jurisdiccional en materia de privacidad y protección de datos en todo el mundo, como afirma Fleisher ${ }^{17}$ : la del ámbito de la organización que utiliza los datos;

\footnotetext{
15 Buttarelli, G. (2011): “Los menores y las nuevas tecnologías”, en AAVV (director Piñar Mañas), Redes sociales y privacidad del menor. Solventia, Editorial Reus, Madrid.

16 ButTarelLi, G. (2011): “Los menores y las nuevas tecnologías”, ob. cit.

${ }^{17}$ Fleisher, P. (2011): “¿Qué legislación en materia de privacidad debería aplicarse en Internet a nivel mundial?” en AA.VV. (director Piñar Mañas), Redes sociales y privacidad del menor. Solventia, Reus, Madrid.
} 
la ubicación de las personas cuyo tratamiento de datos se emplea y por último, el lugar donde se acomete el procesamiento real de los datos.

\subsection{1 Ámbito de la organización que utiliza los datos.}

Esta opción encuentra su fundamento en el artículo 4 (1) (a) de la Directiva sobre protección de datos de la UE, conforme a la cual, es el lugar de origen de la organización el que determina la aplicación de la legislación, tal sería el supuesto que se sigue en Canadá, donde la Ley Federal de protección personal y documentos electrónicos (Federal Personal Information, protection and Electronic document Act (PIPEDA), regula la recopilación, uso y divulgación de información personal.

En este caso, la ley se aplica a una organización se aplica a una organización que se halle establecida en dicha jurisdicción, al margen del lugar donde se produzca el procesamiento real de los datos.

En el supuesto de la UE, en caso de que la organización se encuentre establecida en varios Estados miembros, habrá que adoptar las medidas precisas para que cada uno de dichos establecimientos, cumpla las obligaciones previstas por el Derecho Internacional aplicable.

\subsubsection{Ubicación de las personas cuyos datos han sido objeto de tratamiento}

Es el sistema adoptado en la Ley General de la privacidad infantil en Internet (Federal Children's on line Privacy Protection Act, COPPA), y las leyes sobre violación de protección de violación de datos, aprobadas por la mayoria de Estados. Conforme a este método, se notifica al interesado la violación de datos grave que afecta a una persona (menor), al margen del lugar donde se haya producido la infracción. Tal es el supuesto que se sigue en EEUU, así como en Australia.

\subsubsection{Ubicación conforme al lugar en el que se produce el procesamiento real de los datos.}

La adopción de este planteamiento por parte del artículo 4(1) (c) de la Directiva de la UE sobre protección de datos, funda la competencia jurisdiccional en función del uso de medios situados en la UE, aunque la organización no esté ubicada en la Comunidad Europea. Este método es, de igual modo, el que se sigue en otros países, como Argentina e Israel.

La diversidad de estos distintos sistemas que hemos señalado para determinar la aplicación jurisdiccional en materia de protección de la privacidad de datos en las redes, conduce a que, a menudo, las organizaciones que utilizan Internet y aquéllas que contratan a proveedores de servicios mundiales, sean objeto de legislaciones de diferente tipo de jurisdicción.

5. Proyección de los riesgos de redes sociales sobre los Derechos de la personalidad del menor: Conveniencia de una regulación unitaria de la UE.

El entorno virtual y redes sociales comportan potenciales riesgos contra la intimidad y dignidad de los menores, que no resultan plenamente soslayables con la legislación actual, como afirma Fernández Pérez ${ }^{18}$. El uso frecuente de Internet por los menores, les hace particularmente vulnerables, lo que comporta una serie de peligros

18 Fernández PÉREZ, A. (2016), "La protección de los Derechos fundamentales de los menores en Internet desde la perspectiva Europea.", en Ius et Praxis, vol. 22, n 1, Talca. 
que este colectivo puede encontrar en la red, como son: pornografía infantil, intercambio de material con contenido violento, acceso a servicios legalmente restringidos o inapropiados para su edad, exposición a publicidad ofensiva, robo de datos de identidad y otros riesgos similares que, existiendo, pueden ser al menos parcialmente sorteados si se tiene información acerca del funcionamiento y políticas de privacidad en la red y una educación de su adecuado uso.

La rápida evolución de tecnología de las TICs y su forma de relación social, puede producir una situación de indefensión por parte de los menores, tan proclives a la información personal, hasta el punto que más que intimidad, se puede emplear el concepto de eximidad en las redes, y por tanto, quedando expuestos con un uso inadecuado de tales medios, por terceras personas.

Conscientes de esta situación de desamparo de los menores frente a las redes sociales e Internet, las instituciones públicas deben adoptar una decidida acción de defensa orientada a prevenir vulneraciones de la confidencialidad, integridad y otros abusos del sistema informático en relación con el menor.

En este orden la UE está trabajando en la unificación de una normativa europea que proteja de manera igualitaria entre los estados miembros frente al fenómeno digital. La dimensión global de Internet hace difícil la aplicación de leyes estatales, al ser únicamente aplicables territorialmente, cuando los responsables de conductas ilícitas se encuentran en otros países. A esta circunstancia responde la Directiva 2000/31/CEdel Parlamento Europeo y la Directiva sobre Comercio electrónico transpuesta en España por la LEY 34/2002 de Servicios de la Sociedad de la información, cuyo Capítulo III (artículo18) está destinado a los códigos de conducta de los proveedores de Internet atendiendo a los procedimientos necesarios para detectar y retirar contenidos ilícitos teniendo en cuenta la protección de los menores y dignidad de la persona.

Tras una serie de instrumentos redactados sobre la materia, entre los que se puede mencionar el "Libro verde sobre la protección de los menores y de la Dignidad humana en los servicios audiovisuales y de información", el Consejo emitió su Recomendación de 24 de Septiembre de 1998 relativa al desarrollo de servicios audiovisuales y de información en línea, destinada a lograr un nivel de protección comparable y efectivo de los menores y de la dignidad humana (98/560/CE). Tal Recomendación instaba al establecimiento de un clima de confianza que descansara en la adopción de medidas eficaces de protección de los menores y de la dignidad humana, así como la creación de marcos nacionales de autorregulación, al objeto de lograr una normativa europea que proteja de manera igualitaria en este aspecto a todos los miembros de la UE.

\section{La influencia de las redes sociales entre los menores en los Centros Educativos: Su impacto emocional.}

La falta de conciencia por parte de los menores conlleva insertar información en las redes que no va acompañada del correcto nivel de privacidad, como afirma Ramón Fernández ${ }^{19}$, y que puede ser vista por cualquier persona y utilizada sin consentimiento, lo que supone adentrarse en un área no exenta de riesgos y con consecuencias jurídicas para los menores que interactúen en tal esfera sin respeto 19 RAMÓN FERNÁNDEZ, F. (2015), "Menores y redes sociales: Cuestiones sociales", en Revista sobre
infancia y adolescencia, 8, Abril 2015

(C) UNED. Revista de Derecho Politico

N. 100 , septiembre-diciembre 2017, págs. 1271-1308 
mínimo a la privacidad, como pone de manifiesto Aba Catoira ${ }^{20}$, e incluso convertirse en una víctima de las redes sociales. Los riesgos del menor no sólo se cifran en aspectos tales como: intercambio de información de datos no adecuado, aceptación social por terceros, subida de imágenes, contacto arriesgado con desconocidos, etc., sino que las redes encierran otros peligros que, aunque tienen apariencia de juegos entre jóvenes y adolescentes, pueden provocar auténticos perjuicios de tipo emocional en los menores, siendo muy fácil su accesibilidad ya que no requieren de ningún tipo de registro para su control y que en muchas ocasiones encuentran un buen caldo de cultivo en los Centros educativos, particularmente proclives, por la concentración de adolescentes, a integrarse e interactuar en estos medios tecnológicos de la información y comunicación. Conforme a una encuesta realizada por el Instituto Nacional de Estadística, el 95,2\% de los menores entre 10 y 15 años usa ordenador, y el 91,8\% Internet y el 63\% tiene móvil.

El menor no es consciente en términos generales de la información que facilita. En la mayoría de las veces vulnera las normas básicas de privacidad. A la vez, la transversal aplicación de los dispositivos a través de los cuales se puede navegar en la red e Internet, amplía considerablemente el ámbito de relaciones sociales entre jóvenes y adolescentes, que encuentran en este medio su modo habitual de relacionarse, volcando en ellos gran parte de sus datos personales, definiendo su perfil en las redes $y$, en definitiva, acuñando nuevos modelos de interactuación, particularmente atractivas por su interactividad y como medio de intercambio de datos. Riesgos como el engaño, inserción de fotografías que reflejan su vida cotidiana, aspectos sexuales o intimidatorios, amenazas, entre menores, pueden llevar a las TICs, de ser un medio de relación social beneficioso, a convertirse en un dispositivo de tormento entre menores.

Este tipo de acciones que se suelen plantear en relación al uso de las nuevas tecnologías pueden afectar a varios ámbitos como el honor, la intimidad e imagen del menor, que alteran su bienestar y el correcto desarrollo de su personalidad, por lo que no sólo la normativa Europea y la legislación interna de cada Estado miembro debe velar por el tratamiento de los derechos del menor, sino que asimismo, la armonización legislativa debe ir pareja con los distintos ámbitos de aplicación en los que se ubica el medio natural en el que los menores habitualmente extienden sus relaciones, como los centros educativos.

Desde esta consideración, se hace obligada la formación de la juventud e infancia conforme a unas pautas, proyectando distintos tipos de acciones por parte de las instituciones públicas y la administración, fomentando especialmente la educación de los menores, ya con carácter preventivo desde los centros educacionales.

\section{PLANES DE PROTECCIÓN EN LA CONVIVENCIA DEL MENOR Y LAS REDES EN LOS CENTROS EDUCATIVOS. POSICIÓN DE NUESTROS TRIBUNALES SOBRE LA RESPONSABILIDAD DE LOS CENTROS EDUCATIVOS.}

La Administración Educativa, consciente del progresivo incremento de los problemas de convivencia en los centros educativos, ha dado como respuesta la necesidad de emprender actuaciones para la mejora de convivencia en tales centros en las dos direcciones, docente y discente, reconocidos como Planes de convivencia, tal

\footnotetext{
20 Aba Catoira, A. (2011), "Protección de los Derechos de los menores ante las nuevas tecnologías: Internet y redes sociales", en COTINO HUESO (Coord.), Libertades de expresión e información en Internet y las redes sociales: Ejercicio, amenazas y garantías.Universidad de Valencia.
} 
como indica Fernández Tilve ${ }^{21}$, orientados a solucionar los problemas que derivan de conductas agresivas frente a otros compañeros en los centros escolares y que van desde la consciente y deliberada agresión física, a la psicológica, planes éstos de tipo inclusivo, en los que se coordinan profesorado, alumnado y familiares, sin cuya implicación en este trípode, tales planes serían ineficaces.

El objeto de los Planes de convivencia escolares se cifra en llevar a cabo acciones de prevención ya en el ámbito educativo, desde temprana edad, y la solución de las dificultades de convivencia, a través del fomento de ésta como acción colectiva, enseñando a convivir con los conflictos, proponiendo soluciones pacíficas de los conflictos y tratando de minimizar y prever manifestaciones de violencia a través de la creación de condiciones adecuadas para que exista un clima adecuado que favorezca la convivencia constructiva de tal modo, que pueda institucionalizar el modelo de convivencia de un Centro, en el que se cifran objetivos, actuaciones, temporalización, procedimiento, recursos etc., que culminan en un proyecto educativo.

Nuestros tribunales se han manifestado vacilantes en torno a la responsabilidad de los centros docentes en los casos de conflictos de menores, como abunda Colás Escandón $^{22}$, lo que se pone de relieve en distintas sentencias, como en la STS, Sala $1^{\text {a }}$, $n^{\circ} 1039 / 1996$, de 10 Diciembre en que enjuiciaban los daños causados por niña de 4 años que llevó al colegio una chapa con imperdible que en una discusión le clavó a otro niño en el ojo causando graves daños. En este caso, el TS afirmó que el responsable era el Centro escolar, ya que el daño se originó en el colegio y en horario escolar.

Sin embargo, otra sentencia del mismo año STS, sala $1^{a} n^{\circ} .114 / 1996$, de 23 Febrero, sobre la que en una colonia de verano en la que una menor fallece como consecuencia de una enfermedad crónica, que no había sido comunicada por los padres a los responsables, y en la que aprecia la concurrencia de responsabilidades entre responsable del centro y padres. Particularmente significativa en tema de acoso es la Sentencia de la AP de Álava, secc. $2^{\mathrm{a}} \mathrm{n}^{\mathrm{o}}$. 53/2008 de 12 Diciembre ante un supuesto de bullying, en el que considera reprochable la falta de conocimiento de la situación de acoso por parte de los educadores, la no adopción de medidas, el erróneo diagnóstico responsabilizando al menor de su situación, y considerando al Centro responsable del quebrantamiento moral del menor.

El Tribunal Superior de Justicia del País Vasco, en Sentencia num. 93/2011, de 8 Febrero, tuvo ocasión así mismo de pronunciarse sobre un caso de bullying escolar con resultado de suicidio del menor, en relación a la responsabilidad del Centro escolar, y respecto al que el Tribunal se pronuncia considerando totalmente diligente la actuación del Centro escolar en este caso, invocando que los daños no se producen sólo, ni siquiera fundamentalmente en el Centro, sino también fuera de él, e invocando que cualquier efecto dañoso que se produce en un Centro no necesariamente implica responsabilidad del mismo, y menos en este caso, considerando que no ha mediado culpa in vigilando.

\section{APROXIMACIÓN CONCEPTUAL A DIVERSAS MANIFESTACIONES DE RIESGO SOCIAL DEL MENOR.}

\footnotetext{
${ }^{21}$ FernÁndez Tilve, M. D.:” El plan de convivencia...”, op. cit., pág. 22.

22 Colás Escandón, A. (2015): Acoso y ciberacoso escolar. La doble responsabilidad Civil y Penal. Wolters Kluver, Barcelona, 2015, pág. 384.
} 
Existe una cierta imprecisión conceptual en torno a este ámbito, debido a la inexistencia de concepto jurídico expreso referente a términos tales como ciberacoso y ciberbullying, dando como consecuencia, cabida a una amplia gama de conductas que supondrían un riesgo social del Menor. De hecho se puede afirmar que esta imprecisión incluso también sucedía con los propios términos de acoso y de bullying, que por no tener una regulación penal, una regulación penal específica, no sólo no había un consenso claro sobre su alcance, sino que englobaban conductas de lesividad para los intereses en juego, muy dispares entre sí.

El presente trabajo aborda el análisis de la diversa respuesta a las diferentes variedades de acoso a menores, la mayoría de ellas en el ciberespacio, con la complicidad del anonimato, en alguna de ellas, lo que hace más lesivo el daño que se puede infligir al Menor.

El objeto de estudio no es, por tanto, sólo el estudio del acoso de mayores a menores realizado a través de Internet, ya sea de forma continuada y sistemática, o si se se limita a la realización de acciones individuales de acoso que pueden enmarcarse en delitos contra el honor, la libertad o bienes jurídicos similares, por lo que en el presente trabajo trataremos de identificar conceptualmente estas figuras de riesgo del Menor, partiendo de la tipificación del propio alcance que le ha atribuido la psicología y la criminología al término acoso, como son : ciberacoso, bullying, ciberbullying, grooming, sexting y morphing, para poder diferenciar las distintas conductas así como su distinta gravedad para la dignidad, libertad, honor, intimidad y otros bienes personalísimos de los menores que se ven puestos en peligro en la actualidad, en el ámbito del ciberespacio, con una abierta vulneración de la prescripción constitucional del artículo 20.4 CE de los derechos de la personalidad del menor, así como por contravenir la especial protección con la que la Constitución reconoce a la juventud e infancia en este ámbito de las libertades informativas y que tiene reconocido el Tribunal Constitucional ${ }^{23}$.

Así, con carácter general y, por tanto, aplicable a las diversas acepciones que puede revestir un episodio de acoso, entendemos por éste, conforme a la $\mathrm{RAE}^{24}$ "La persecución o apremio inoportuno a una persona con molestias o requerimientos". Desde esta aproximación inicial, común denominador para otros tipos específicos de hostigamiento, se construyen otras figuras de evidente riesgo social para el menor como los neologismos anteriormente mencionados, que comparten una serie de puntos en común, reconociéndose en alguno de ellos similitudes tales como: el acorralamiento de una persona, o grupo de personas hacia un menor, que tal hostigamiento tenga carácter repetido en el tiempo y que suponga un riesgo para la libertad e integridad del menor.

De las diversas manifestaciones que puede revestir el acoso, nos referiremos a continuación a aquéllas que con más frecuencia pueden originarse en la etapa escolar y educacional de los menores, es decir infancia y adolescencia.

\section{El menor ante episodios de acoso como factor de riesgo social.}

Por acoso entendemos, tal como mencionamos anteriormente el apremio inoportuno a una persona, ya sea con molestias o requerimientos, pero que, a su vez, puede ser invocado como método o sistema común que sirve de base para otras manifestaciones de riesgo para el menor, ya sean de tipo presencial o telemático., como

${ }^{23}$ STC 5/81, de 13 de Febrero. Recurso de inconstitucionalidad no 189/1980 contra algunos preceptos de la Ley Orgánica de Centros Educativos (LOECE).

24 Diccionario RAE, edic. 1992. Y también acoso moral: Práctica ejercida en relaciones personales consistente en dispensar trato vejatorio a una persona con el fin de desestabilizarlo psíquicamente.

(C) UNED. Revista de Derecho Político 
señala Quicios García ${ }^{25}$, tales como el bullying, ciberbullying, ciberacoso, grooming, sexting, y morphing.

Sin perjuicio de las diferencias intrínsecas a cada una las figuras de riesgo del menor mencionadas, existe una serie de notas comunes a todas ellas de hostigamiento al menor y que podemos resumir en lo siguiente:

a) Suponen una actuación de acorralamiento hacia una persona que no recciona con mecanismos de defensa frente a la agresión que soporta, lo que se puede traducir en secuelas y daños psicológicos, psicosomáticos y, o, depresiones.

b) Casi todas ellas revisten un prototipo de violencia no física, exceptuando el bullying, hacia su víctima.

c) Persiguen originar un daño psicológico que se repite en el tiempo y provoca la doble victimización del sujeto que lo sufre.

d) De todo ello cabe señalar que existe un método de hostigamiento al menor a través de las ciber redes de violencia psicológica, con carácter general y que las diferentes manifestaciones a través de las cuales tal acoso se plasma, difieren según los distintos bienes jurídicos de los menores vulnerados: honor, libertad, intimidad, entre otros lo que delimitará la concreta manifestación jurídica de la manifestación de acoso, y, en consecuencia, la gravedad del ilícito.

\section{La vulnerabilidad del menor frente al ciberacoso: Factor de riesgo emocional}

\subsection{Concepto de Ciberacoso.}

Muy similar a la figura del acoso propiamente dicha,puede definirse como la amenaza, molestia, y hostigamiento que una persona ejerce sobre otra, pero diferenciándose del acoso, por verificarse esta conducta ilícita, a través de las diferentes tecnologías informáticas, sea por chats, o mediante páginas web, correo electrónico, telefonía móvil,cámaras digitales, etc., siendo precisamente el medio a través del cual se producen los efectos del acoso, el motivo por el que se reconoce la figura de ciberacoso, y que se traduce - más allá del acoso - en una "agresión psicológica sostenida y repetida en el tiempo, perpetrada por uno o varios individuos contra otro, que no sabe o no puede defenderse eficazmente", utilizando para ello las técnicas de la información y de la comunicación (TICS).

Por otra parte, el ciberacoso se diferencia a su vez de otra figura similar, ciberbullying, la cual suele darse en centros escolares, y siempre entre menores, de forma que acosador y acosado son menores.

\subsection{Contenido dela figura de ciberacoso.}

El ciberacoso, como acción intencional de agresión social, se ejercita de manera persistente, a iniciativa de uno o varios agresores que permanecen ocultos y que se caracteriza por las siguientes notas:

- Hostigamiento, humillación y molestia del ciberacosador a su víctima.

- Acción ilícita verificada mediante las nuevas tecnologías.-

25 Quicios García, P. y Moreno, R. (2012): "Riesgos emergentes en las relaciones entre niños: Acoso, ciberacoso, bullying, ciberbullying grooming", en Menores en crisis (coord. Fernández Tilve y Suárez Sandomingo), Universidad de Santiago de Compostela, pág. 521

(C) UNED. Revista de Derecho Politico

N. 100 , septiembre-diciembre 2017, págs. 1271-1308 
- Continuidad en el tiempo de manera que un hecho aislado no supondría figura de ciberacoso, aunque las consecuencias de un simple hecho puntual, en el ámbito virtual del acosado, puede suponer un sufrimiento prolongado.

- El ciberacoso no se circunscribe exclusivamente al ámbito escolar o académico, sino que puede afectar a los usuarios de las TICS, con carácter general y con independencia de edades.

- Daño de la imagen telemática de la víctima y de su concepto personal.

- Supone una agresión telemática no controlada, pues invade todos los espacios donde llegan las TIC, provocando en la víctima impotencia e indefensión.

- Facilita en gran medida el anonimato e impunidad del ciberacosador

- El grado de categoría de la agresión es muy amplio dependiendo de la habilidad y pericia telemática del ciberacosador y de su perversa imaginación.

Conforme a la descripción anterior, cabe formular un marco de distintas categorías de la morfología de la agresión, atendiendo al grado de menor a mayor hostigamiento que se inflige a la víctima y que siguiendo a Quicios García ${ }^{26}$ podemos formular en las siguientes:

- Acorralamiento, mediante persistente envío de mensajes ofensivos a través de los espacios de comunicación en la red, en los que toma parte la víctima.

- Ultraje, a través de informaciones injuriosas o dañinas sobre la víctima, o revelando secretos sobre la misma, en la red

- Desafío, con calificaciones degradantes y peyorativas sobre el ciberacosado para dañarle, sin poder defenderse en la red.

- Descarte, supone la eliminación, directamente, de la víctima de los espacios de la red en los que toma parte.

- Robo de imagen a través de la asunción falsa de la personalidad de la víctima creándola conflictos con otros e-usuarios.

\subsection{Objetivos del ciberacosador}

La finalidad del ciberacosador es lesionar o dañar determinados derechos, básicamente los derechos de la personalidad, honor, intimidad y propia imagen, y la protección de la juventud e infancia (artículo 20.4 CE) que guardan estrecha relación con la dignidad de la persona (artículo 10.1 CE) y su integridad moral (artículo $15 \mathrm{CE}$ ), sin exclusión de la eventual vulneración de otros bienes jurídicos, pero que de manera más frecuente, son los mencionados.

Como ejemplos ilustrativos a través de los que se practican estos episodios de ciberacoso podemos referir: el acceso a los correos electrónicos o sms de otras personas, la difusión de informaciones falsas o intimas de otras personas en la red, subir a Internet fotografías o videos de personas que no han dado su consentimiento, etc.

Es particularmente representativo en la temática que analizamos el un estudio estadístico sobre un cuestionario de investigación hecho a un representativo grupo de jóvenes en Andalucía: "Escenarios, tecnologías digitales y juventud"27, en el que se

${ }^{26}$ Quicios GarcíA, P y Moreno, R. (2012): "Riesgos emergentes en las relaciones entre niños: Acoso, ciberacoso, bullying, ciberbullying grooming" en Menores en crisis (coord. FERNÁNDEZ Tilve y SuÁREZ SANDOMingo), Universidad de Santiago de Compostela, pág. 524.

27 Bernal Bravo, C. y Angulo - Rasco, J. F. (2013), "Interacciones de los jóvenes andaluces en las redes sociales" en Comunicar, núm. 40 Vol. XX, págs. 25 y 30 
refleja la importancia que atribuyen los jóvenes al perfil que adoptan a la gestión de su privacidad y seguridad en la red, ante el temor a situaciones de acoso y abuso, por miedo a insultos, injurias o publicación de fotos que desacrediten su perfil.

En este sentido el estudio refleja dos tipo de acoso: el que deriva de discusiones o peleas ó simple discordancia de criterios (39/\%), y el que deriva por episodios de rivalidad o envidia (38/\%), siendo la agresión verbal el medio más usual, como también, el que viene definido por estereotipos sobre los que activar procesos de ciberagresión, como es el caso del perfil del "friky", o del "empollón", o del "líder".

En definitiva, el objetivo final de estas conductas en el ciberespacio es provocar daño psicológico y emocional al ciberacosado, a través de amenazas y de su humillación y desprestigio en la red.

\section{Marginación del menor por maltrato escolar. Bullying}

\subsection{Concepto del Bullying}

Por este tipo de acoso, conforme la definición dada por Olweus ${ }^{28}$ y la más aceptada en la doctrina, cabe entender la situación en la que" un alumno está expuesto repetidamente y a lo largo del tiempo a acciones negativas de otro u otro grupo de estudiantes menores", lo que comporta un supuesto de maltrato escolar.

Este concreto escenario del centro escolar como ámbito en el que se desarrolla el episodio de bullying, es precisamente el que lo diferencia de otros tipos de maltrato entre menores en la red y del ciberbullying que respondería a este tipo de mal trato entre estudiantes, sólo que, en el ciberespacio. Para que exista ciberbuyiing, tanto atacante como atacado, deben tener aproximada edad entre iguales, como afirma Davara Fernánde $z^{29}$, que supone el traslado al mundo digital el acoso escolar, con el añadido de ubicuidad, mayor exposición temporal y el anonimato junto a la suplantación de identidad.

El Bullying es un anglicismo configurado por Dann Olweus en 1972 conforme al gerundio de la forma verbal inglesa de la palabra bully, de la que deriva, que significa matón, por lo que en una traducción libre puede entenderse por bullying como la acción de amedrentar a un escolar por parte de otro, para conseguir lo que se quiere .En la actualidad, su el estudio de esta figura en los centros socioeducativos, está muy presente por las repercusiones que estos episodios de bullying comportan en tales ámbitos entre los menores.

\subsection{Contenido del Bullying}

Toda acción de bullying refleja una manifestación de riesgo presencial que se produce entre menores que son compañeros de estudios y permanece en el tiempo, siendo características propias de esta dañina relación presencial,,además de las mencionadas, que se realiza de manera silenciad por un individuo o por un grupo de personas que obedecen a su líder o ideólogo que permanece en la sombra,que ha optado por una determinada víctima y una manera de dañala. Su objetivo es producir

\footnotetext{
28 OlweUs, D. (1998), Conductas de acoso y amenaza entre escolares. Morata, Madrid 1998, pág. 25.

29 Davara Fernández, E. y L. (2017), Delitos informáticos, Coord. Davara Rodríguez, M. A., Thomson Reuters, Aranzadi, Pamplona.
}

(C) UNED. Revista de Derecho Politico 
perjuicios psicológicos a la víctima, sin aparecer nunca el agresor líder, sino quienes se ocupan de la agresión física al compañero.

Conforme a ello el bullying podría representarse como una pirámide en la que cada vértice correspondería, respectivamente, a la víctima, el líder o ideólogo y el acosador o matón, utilizándose para acometer este tipo de maltrato factores como : bromas pesadas, amenazas verbales, burlas, desprestigio, intimidaciones, ridiculizaciones e insultos, humillaciones, robos, ruptura de ropa, etc.

Existen tres elementos identificadores de este tipo de maltrato -bullying presencial- que conforme a Miró Linares ${ }^{30}$, puede concretarse en las notas de: intencionalidad de infligir el daño, repetición en el tiempo y desequilibrio o abuso de poder de un menor sobre otro menor, esto es, entre iguales, dentro del ámbito escolar y por tanto, con carácter presencial y físico.

\subsection{Objetivo de la agresión por Bullying.}

No es mucho más distinto de la finalidad que tiene, a su vez, el ciberbullying, pero en lo que sí difieren es en el ámbito en el que se acometen estos abusos presencialmente o en la red, respectivamente - teniendo como particularidad el supuesto del bullying presencial, que con mucha frecuencia, lo que comienza adoptando una manifestación de bullying presencial, físico, termina derivando en una acción de ciberbullying, como con acierto señala Marco $\mathrm{Marco}^{31}$, de igual modo que un conflicto on line, entre compañeros, puede convertirse en un caso de bullying, al trasladarlo al ámbito escolar.El objetivo pues del bullying es ridiculizar y humillar a la víctima de bullying, por parte de un compañero que ejerce el liderato, quedando este papel más diluido en los supuestos del ciberbullying.

\section{El ciberbullying como variante del ciberacoso.}

\subsection{Concepto del ciberbullying}

El ciberbullying es una variante del ciberacoso, pero en la que tanto el acosador como el acosado son menores de edad - frente a lo que sucede en el ciberacoso, en el que el acosador es un adulto, y la víctima del ciberacoso, un menor- Esta circunstancia de que en los supuestos tanto de bullying, como de ciberbullying se produzca entre menores, en plano de igualdad, no implica que sean figuras de acoso tan similares entre si, ya que difieren ostensiblemente en función del medio a través del cual se produce el daño.

Conforme a la definición de Patchin e Hinduja ${ }^{32}$, entendemos por ciberbullying "El daño intencional repetido e infligido a través de un medio electrónico ", o por su parte, como lo define Smith, "Acción agresiva e intencional desarrollada por un grupo o individuo, usando formas electrónicas de contacto repetidas veces a lo largo del tiempo contra una víctima que no puede defenderse fácilmente, ocasionando un desequilibrio de poder". El ciberbullying se diferencia de otras figuras como el

\footnotetext{
30 Miró Linares, F. (2013): "Derecho Penal, Ciberbullying y otras formas de acoso no sexual en el ciberespacio", en Revista d'Internet, dret i Politica, IDP nº 16 junio, pág 64.

31 Marco Marco, J. (2010), "Menores, ciberacoso y derechos de la personalidad", en García GONZÁLEZ (coord.), Ciberacoso: La tutela penal de la intimidad, la integridad y la libertad sexual en Internet, Tirant lo Blanch, Valencia, pág. 100.

32 Patchin J. W., y Hinduja, S. (2006), "Bullies move beyond the school yard: a preliminary look at cyberbullying", en Youth Violence and Juvenile Justice, 4(2), pág. 152.
} 
Cyberstalking y el cyberharassement, que suponen una conducta de acoso a adultos de forma no continuada en el ciberespacio.

\subsection{Contenido del ciberbullying.}

Conforme a su definición cabe entender el episodio de Ciberbullying como el abuso de poder continuado de un menor sobre otro realizado por medio de las TIC, manifestándose en conductas proclives a atormentar, humillar, y angustiar al menor, pero que en este caso, ya no se cometen en el escenario físico de la escuela o centro escolar, ni ningún otro espacio geográfico, sino en el ciberespacio, lo que suele comportar que cambien los agentes o autores de esta forma de acoso.

Por otra parte este tipo de conducta está definida por una serie de características que definen al bullying, entendido en un sentido general, es decir, intencionalidad, repetición, y desequilibrio de poder, pero que, el especial instrumento a través del cual se verifica este concreto tipo de acoso, añade matices diferenciadores a esta específica forma de bullying en la red, como son : el anonimato, el carácter público de la agresión y que la misma se pueda acometer sin límites espaciales ni temporales, y en el anonimato, y mayor impunidad del hecho,como afirma Calmaestra ${ }^{33}$. Pero quizás una de las mayores diferencias entre estas dos figuras de riesgo social del menor radique en las estrategias con las que se aborda al menor y por tanto, las consecuencias que de ello derivan. Estas diferencias siguiendo a Marco $\mathrm{Marco}^{34}$, se cifran en:

- En el ciberbullying el papel liderato entre los acosadores está más diluido.

- La imagen de matón -bully- o del fanfarrón, en el ciberbullying no es tan característica como en el bullying, por lo que no se necesita ser fuerte fisicamente para acosar en la red.

- Aunque en el ciberbullying no hay maltrato físico, los efectos de éste pueden ser incluso más devastadores que los del bullying escolar.

- Acosador y víctima no tienen por qué conocerse

- La victimización o daño del efecto del ciberbullying, sin ser físico, es más devastador que el del acoso escolar.

\subsection{Manifestaciones del ciberbullying.}

Entre las diversas manifestaciones en que se plasma este tipo de riesgo social para el menor, tales como colgar en internet imágenes comprometidas, tanto si son reales como si son montajes, o subir a la red datos sensibles que pueden avergonzar o desprestigiar a la víctima, crear falsos perfiles en nombre del menor imputándole asuntos personales o demandas explícitas de contactos sexuales, o colgar comentarios ofensivos en foros del chat, dar de alta la dirección del correo electrónico de la víctima para molestarla con spam, subir a la red rumorología que refleje una conducta ofensiva o desleal, etc, todas ellas van orientadas a desprestigiar al menor sujeto pasivo de ciberbullying.

\footnotetext{
33 CAlmaestra, J. (2011): Cyberbullying: Prevalencia y caracteristicas de un nuevo tipo de bullying indirecto. Tesis doctoral Servicio de publicaciones Universidad de Córdoba, pág. 48.

34 Marco Marco, J. (2010), "Menores, ciberacoso y derechos de la personalidad", en García GONZÁlEZ (coord.), Ciberacoso: La tutela penal de la intimidad, la integridad y la libertad sexual en Internet, Tirant lo Blanch, Valencia.
}

(C) UNED. Revista de Derecho Político

N. ${ }^{\circ} 100$, septiembre-diciembre 2017, págs. 1271-1308 
Esta situación va creando un caldo de cultivo que provoca profundos perjuicios psíquicos y emocionales y educativos en el menor, problemas de adaptación escolar, baja autoestima, ataques de ansiedad y, en ocasiones, llegar al suicidio.

En este contexto cabe plantearse el motivo por el que, cada vez más frecuentemente se producen situaciones de ciberacoso en los centros escolares, lo que resulta debido a la confluencia de diversos factores como: falta de control paterno, excesivo tiempo navegando en la red, ausencia de valores, etc. Para algún sector de la doctrina - González Esteban - es la escala de valores la que está en peligro, lo que requiere cerrar filas en torno a un sólido sistema preventivo, al que nos referimos más adelante.

\section{El Grooming como manifestación de maltrato y abuso en la indemnidad del Menor.}

Ésta es un exponente visible de ciberacoso que realiza un adulto a un menor desde un medio telemático, como un abuso sexual virtual. La Ley Orgánica 5/ 2010 de 22 junio de reforma del Código penal tipificó el child grooming (artículo 183 bis). Conforme a un sector de la doctrina representado por Gorriz Royo ${ }^{35}$ considera que aunque no hay una precisa y unívoca acepción conceptual para esta figura de abuso del menor, que conduce a una falta de unanimidad acerca de un conepto técnico jurídico para abarcarlo, sin embargo, hay una serie de notas que apuntalan esta figura, tales como que se trata de un proceso, la existencia de un contacto que favorece un acercamiento en el que se desarrolla una acción capciosa, que finalmente conduce a un encuentro físico entre el menor y el adulto

Así se va generando un proceso de contacto y eventual establecimiento de relación de confianza entre el sujeto que actúa el grooming y el menor, como señala Diaz Cortés $^{36}$, que puede acometerse, no sólo a través de internet, sino de cualquiera de las TICS, pero lo que realmente tipifica como delito al grooming es que tal relación de confianza del child grooming - del sujeto con el menor - es que el adulto realiza el acercamiento al menor con el fin de abusar sexualmente de él (Child following sexual grooming through TICS), como contacto a través de las TICS preordenado a la actividad sexual con menores.

En términos coloquiales sería algo así como preparar el terreno para cometer un ilícito sexual contra el menor.

\subsection{Objetivo del grooming.}

Éste tiene siempre connotaciones eróticas y su finalidad es el consumo sexual con el menor, siendo el acercamiento al menor por va virtual, pero su objetivo es la relación física sexual con la víctima menor.

En esta figura de riesgo del menor hay que señalar que el sujeto pasivo, esto es la persona que resulta dañada en su indemnidad es el menor de 13 años, ya que superada esta edad, entiende el legislador que el menor puede dar su consentimiento en materia sexual. En definitiva, se trata de una relación de abuso de un adulto que se prevale de la inocencia o irreflexión infantil, haciéndose pasar por otro adolescente, intentando

\footnotetext{
35 GÓRrIZ ROYO, E. (2016), “ON-line childgrooming desde las perspectivas comparada y criminológica como premisa de estudio del artículo183 ter $1^{\circ}$ CP”, en Menores y redes sociales (Dir. CUERDA ARNAU, coord. FERNÁNDEZ HERNÁNDEZ), Tirant lo Blanch, Valencia.

${ }^{36}$ DíAz CORTÉs, L.M. (2011), "Algunas consideraciones sobre el meeting A child following sexual grooming throught tics" (Contacto tics preordenado a la actividad sexual con menores)", Cátedra de Telefónica de la Universidad de Salamanca. Mayo 2011, pág. 7.
} 
recabar durante un tiempo información y datos personales y familiares del menor como nuevo amigo virtual.

Una vez obtenida la confianza del menor, éste le facilita toda la información requerida sin violentar ni molestar al menor.Una vez obtenida, el ciberabusón despliega su verdadero objetivo: engañar a la víctima para conseguir imágenes de tipo erótico que posteriormente utilizará como medio de extorsión, para coaccionar al menor y entonces, ya sí, conseguir mantener relaciones sexuales con el menor amenazado.

\subsection{Secuelas del Grooming en el menor.}

La víctima de este proceso lo oculta por vergüenza a los adultos que pueden protegerle y el padecimiento del menor puede dejarle secuelas físicas y psicológicas, y en el supuesto que intentara romper la relación con el adulto, éste intentará destruir la imagen de su víctima a través de las tics, softwares, redes sociales, etc, practicando con esta conducta otra manifestación social de riesgo telemático como ciberacoso, situándose en la antesala de otro delito aún más grave : pedofilia o abuso físico.

La tecnología punta en dispositivos electrónicos e informáticos permite con máxima facilidad enviar todo tipo de imágenes y mensajes por Internet, esta potenciación de la comunicación y acceso a las redes sociales y comunicaciones virtuales como Messenger, Tuenti, Facebook, etc, permite a los individuos con esta inclinación perversa, escoger entre muchos perfiles a su víctima; siendo la franja de edad de los adolescentes la comprendida entre 10 y 15 años, y la del perfil de los acosadores entre 30 y 50 años.

La técnica más usual para realizar el childgrooming por parte de un pedófilo suele ser la siguiente:

-Acceso a salones de chat con nombres llamativos para el niño o niña.

-Elige al niño que tiene un perfil de nick similar al suyo y tras establecer un chat, le pide su dirección de Messenger

-Le pregunta si tiene Webcam para conocerlo mejor e ir seduciéndole con cosas bonitas pidiendo le que adopte poses insinuantes que son captadas en formato jpg en su ordenador, y pidiéndole cada vez cosas más comprometedoras y amenazándole con enseñar las fotos captadas a su familia o a un fotolog, si no accede a sus intenciones, iniciando un acoso que puede acabar en un abuso sexual., desarrollándose todo este proceso durante un largo periodo de tiempo que puede durar incluso meses.

\section{El Sexting como factor de riesgo telemático.}

Es uno de los casos de emergente factor de riesgo social telemático de los menores consistente en difundir en las TICS contenidos audiovisuales de naturaleza erótico- sexual, si bien, facilitados voluntariamente por el menor.

Este neologismo deriva de la unión de dos conceptos: sex y texting, que unidos estos anglicismos, conforma sexting. Conforme a esto, hay dos modelos:

+ El sexting textual que es algo similar al teléfono erótico, consistente en enviar un texto de tal contenido desde un terminal telefónico por SMS a un destinatario expresamente elegido.

+ El sexting visual que trata de facilitar, libremente imágenes o sonidos de igual naturaleza, emitidos desde un terminal o web-cam. 
Ambos tipos se dan mayoritariamente entre niñas y en una franja de entre $12 \mathrm{y}$ 13 años, que quieren llamar la atención sobre sí mismas en una linea erótica.

Esta actitud social telemática no está penada por la ley, y no porque haya un vacío legal al respecto, como señala Quicios García ${ }^{37}$-existen la Ley Orgánica 5/2000 de 12 Enero Reguladora de la responsabilidad penal de los menores, así como la Ley Orgánica 5/ 2010, de 22 Junio, que proporciona una mayor protección a los menores y mucho más recientemente la Ley Orgánica 8/2015, de 22 Julio, de Modificación de la Ley Orgánica de Protección jurídica del Menor de 15 enero 1996-, sino que la impunidad de tales actividades, deriva del carácter voluntario del hecho en sí y la falta de coacción, no constituyen, por tanto ilícitos, si bien, puede tener contenidos nocivos.

Esta circunstancia no obsta para que desde determinados ámbitos se inste la protección de los niños contra la explotación y abuso sexual, intentando generar una ciudadanía digital responsable como lo acreditan las directrices emanadas por el Consejo de Europa, así como el Instituto Nacional de Tecnologías de la Comunicación, que por sus parte, facilita contactos donde pueden denunciarse posibles casos de riesgo social y moral infantil por el mal uso de las TICS.

\section{Morphing (Warping)}

Esta modalidad en el mundo relacional infantil en el ámbito de las TICS, se usa para dañar la imagen digital de cualquier e-usuario del que se disponga una imagen digitalizada con la que poder acorralar afectivamente a su víctima.

El procedimiento se sigue a través de una imagen inicial provocando en ella diferentes grados de deformación de la imagen, logrando su distorsión y creando una visión esperpéntica de la misma, pero con un cierto parecido, tal que resulta grotescamente reconocible, convirtiéndola en objeto de burla en las redes sociales.

Esta actividad maliciosa en el ciberespacio, tiene el perverso factor añadido de no estar castigado penalmente, ya que la transformación de la imagen que se realiza, como afirma Quicios García ${ }^{38}$, culmina en una imagen irreal, y al tratarse de una imagen fantástica, legalmente no puede tomarse como prueba, por lo que su creador no puede ser acusado de nada ilegal.Esta impunidad convierte a la víctima agredida, el menor, en sujeto pasivo indefenso y perjudicado frente a sus e-contactos.

El Morphing o Warping, es una técnica de metamorfosis que no tiene, en su origen ninguna finalidad dañina, se trata de retocar secuencialmente la imagen hasta transformarla en otra totalmente diferente, considerándose un arma muy preciada en el mundo artístico para la confección de imágenes no existentes previamente.

Sin embargo, en el objeto de estudio que nos ocupa, su finalidad es absolutamente destructiva e intencional de causar daño al menor desprestigiando su imagen, convirtiéndole en objeto de burla.

\section{PROGRAMA TRANSVERSAL FRENTE SITUACIÓN DE RIESGO SOCIAL Y MORAL DEL MENOR.}

\footnotetext{
37 Quicios García, P. y Moreno, R. (2012): "Riesgos emergentes en las relaciones entre niños: Acoso, ciberacoso, bullying, ciberbullying grooming" en Menores en crisis (coord. Fernández Tilve y Suárez Sandomingo), Universidad de Santiago de Compostela, pág. 543.

38 Quicios García, P. y Moreno, R. (2012): "Riesgos emergentes en las relaciones entre niños: Acoso, ciberacoso, bullying, ciberbullying grooming" en Menores en crisis (coord. FERNÁNDEZ TILVE y SUÁREZ SANDOMINGO), Universidad de Santiago de Compostela, pág. 541.
} 
Los problemas que afectan a menores no pueden ser descontextualizados de su medio, lo que requiere una intervención de las instituciones implicadas para abordar las situaciones de riesgo del menor, a través de programas integrales.

La legislación recoge la obligación de comunicación por parte de toda persona que tenga conocimiento de una situación de riesgo o peligro de un menor, particularmente por parte de quienes, por su profesión, tenga conocimiento de ello, poniéndolo en conocimiento de la judicial u organismo administrativo competente.

El maltrato infantil, en cualquiera de sus manifestaciones de abuso, es un problema social y de salud, de primer orden, siendo el objeto fundamental de la política actual sobre la infancia, que la infancia y juventud puedan ejercer sus derechos de la manera más plena, lo que requiere formación necesaria de los profesionales del ámbito familiar e infancia, para que puedan identificar las situaciones de riesgo desde las primeras señales de alarma para la prevención del abuso, como afirma Fidalgo González $^{39}$, conforme a lo cual cabe formularse distintas áreas en las que cabe preventivamente proteger al menor del impacto de abuso al que puede someterse, para posteriormente pasar a una fase de detección y aplicar una fase de intervención, si fuera necesario.

\section{Métodos de Prevención ante el factor de riesgo.}

Lo mencionado con anteriorioridad hace esencial tratar de prevenir cualquiera de estas conductas antes de producirse, concienciando a los menores, así como a los padres en la educación a sus hijos en el uso responsable de las TICS, y proyectar en los centros educativos, como señala Colás Escandon ${ }^{40}$, las herramientas a su alcance para prevenir el acoso escolar o posible caso de bullying o ciberbullying, instalando políticas y medidas de prevención del acoso. Este tipo de medidas fueron reconocidas en la Conferencia de Utrech el 24 y 25 de febrero de 1997 con el título "Escuelas más seguras."

La prevención no sólo debe orientada a evitar la aparición de casos de maltrato infantil, sino también a su detección precoz y evitar su repetición en los centros educativos. En todo caso, la prevención es el método más eficaz que se puede practicar, proyectándose en diversas maneras, como a través de programas de formación y apoyo a padres; escuelas infantiles, actividades de ocio y tiempo libre, campañas divulgativas, no utilización de la imagen del niño, programaciones de los medios de comunicación adecuados a las correspondientes franjas horarias, conforme determina el artículo 22 de la Directiva 89/552 del Consejo Europeo Televisión sin fronteras: "Adopción de medidas para garantizar que las emisiones de TV no incluyan programas que que puedan perjudicar el desarrollo físico, mental o moral de los menores y en particular, escenas de pornografía o violencia gratuita". nivel:

La fase de prevención de los abusos sobre menores cabe proyectarla en un triple

a) Prevención primaria, dirigida a la mentalización de la sociedad en la crianza de los menores atendiendo a las distintas etapas de su desarrollo y particularmente a:

- Sensibilizar a la sociedad sobre los abusos sociales de los menores.

39 FidAlgo GonzÁLeZ, B. (2012), "Intervención ante el maltrato infantil” en Menores en crisis (coord. FERnÁndeZ Tilve y SuÁrez SANDomingo), Universidad de Santiago de Compostela.

40 Colás Escandón, A. (2015): Acoso y ciberacoso escolar .La doble responsabilidad Civil y Penal. Wolters Kluver, Barcelona, pág. 52. 
- Potenciar equipos profesional sobre este problema y recursos para solucionarlo

- Reducir el contexto social que fomenta el abuso y acoso entre adolescentes.

- Incrementar mecanismos adecuados para que sea cada vez más difícil el maltrato

b) Prevención secundaria. Dirigida a niños y adolescentes pertenecientes a un entorno social para evitar que esa circunstancia derive en una situación de riesgo.

\subsection{Medios instrumentales de prevención}

Partiendo de la premisa de que las TIC configuran la era digital de la generación de la juventud, hay que aceptar una cultura inclusiva de la nueva tecnología, como indica Panizo Galence ${ }^{41}$, para no caer en un absoluto analfabetismo digital.

En esta fase preventiva, conviene recurrir a una serie de medidas previas que ya en sí añaden garantías para evitar riesgos del menor en el ciberespacio, como son:

a) Uso responsable de los dispositivos y TICS en tus relaciones sociales, ya que los ciberacosadores frecuentan este tipo de servicio - web-cam, chats, Tuenti, etc, - en busca de una potencial nueva víctima, por lo que no debe compartirse información confidencial.

b) Relación paterno - filial de confianza, en la que los padres se involucren en la información de los peligros que puede generarse en el anonimato de internet, así como fijando unos horarios para estas actividades.Ayudar a los menores a sensibilizarse respecto al daño que pueden causar a otros compañeros determinado tipo de mensajes, mantener contacto con el entorno educacional de los hijos, y transmitir confianza en los menores sobre eventuales episodios de acoso que pudieran estar sufriendo y hablando con los menores, como señala Pardo Albiach ${ }^{42}$.

c) Existe una amplia gama de herramientas útiles y de control ante la sospecha de que alguien intente violar la seguridad de la navegación en el ciberespacio antimarcadores, anti-virus, anti.spam, etc especialmente contemplados para el malicious software.

\section{Métodos instrumentales de Detección del riesgo.}

La detección de posibles episodios de riesgo de los menores puede realizarse desde el propio domicilio a través de la observación de determinados síntomas externos. También muchos de los casos de abusos se perciben por los educadores de los centros escolares, personal de enfermería, servicios sociales, que en el ejercicio de su profesión llegan a observar una serie de indicadores que les conducen a sospechar que estas situaciones de abuso, se están produciendo.

Entre los indicadores de alarma respecto a episodios de esta índole, cabe señalar:

-Absentismo escolar

-Descuido de aseo e higiene personal.

-Síntomas de malnutrición.

41 PANizo GalenCE, V. (2011): "El ciberacoso con intención sexual y el childgrooming”, en Quadernos de criminología: revista de criminología y ciencias forenses, $\mathrm{N}^{\circ}$. 15, págs. 22-33.

42 Pardo Albiach, J. (2010):” Ciberacoso, ciberbullying, grooming, redes sociales”, en García GONZÁLEZ (coord.), Ciberacoso: La tutela penal de la intimidad, la integridad y la libertad sexual en Internet, Tirant lo Blanch, Valencia, pág. 71. 
-Carencia de incentivo

\section{Intervención.}

En cualquier actuación que se realice en situaciones de riesgo de menores o abusos de menores, el bienestar y la protección del menor debe primar sobre cualquier otra consideración, como queda patente en el artículo 2.2, a) de la Ley Orgánica de 22 de Julio de 2015, de Modificación de la Ley Orgánica de 15 enero 1996, de protección jurídica del Menor, que dispone la protección integral del menor, tanto física y afectiva como emocional.

Como instrumento de intervención cabe asimismo mencionar la figura del agente encubierto, introducida en nuestra legislación por la Ley Orgánica 5/ 1999 de 13 de enero, de modificación de la ley de Enjuiciamiento criminal, que añadió el artículo 282 bis. Su finalidad es crear una identidad imaginaria a un policía, haciéndose pasar por un menor y entrar en los chat frecuentados por ciberacosadores o pederastas, para recabar información, manteniendo incluso conversaciones en el chat o, intercambiándose material para ganar su confianza y poder intervenir culminando su investigación. Quedando exonerado en tal supuesto, de responsabilidad penal de distribución de pornografía infantil ya que se trataría de una investigación necesaria amparada por el artículo 282 bis, apartado 5 mencionado.

El Pleno del Senado, aprobó el 23 Marzo de 2011 una moción del Partido Popular, instando al Gobierno a remitir a las Cortes Generales un Proyecto de Ley de modificación de la Ley de Enjuiciamiento Criminal, así como del Código Penal, para regular la figura del agente encubierto en Internet. Existe figura similar en el ámbito Europeo -Insafe -dependiente de la Comisión Europea de asesoramiento de internet.

\section{LOS DERECHOS DE LA PERSONALIDAD Y LAS TIC COMO POTENCIALES ELEMENTOS TRANSGRESORES DE LA DIGNIDAD DEL MENOR.}

\section{Marco normativo de la dignidad e integridad del Menor}

El marco normativo de ámbito nacional prescribe la dignidad de la persona y libre desarrollo de su personalidad, integridad física y moral, protección de la juventud e infancia, protección de la familia y participación libre y eficaz de la juventud,conforme a los artículos 10-1, 15, 20-4, 27-3, 39-1, 2 y 3 y 48 C. E

Asimismo, constatamos el reconocimiento en Derecho Comparado:

-Artículo 1 de la Ley Fundamental de Bonn de 1949: "La dignidad del hombre es intangible".

-Artículo 3 de la Constitución Italiana de 1947: "Todos los ciudadanos tienen la misma dignidad social y son iguales ante la ley".

-Artículo 1 de la Constitución Portuguesa: "Portugal es una República soberana basada en la dignidad de la persona humana", también el artículo 69 "Los niños tendrán derecho a la protección de la sociedad y del Estado, con vistas a su desarrollo integral" y artículo 70.2: "La política de la juventud deberá tener siempre como objetivo prioritario el desarrollo de la personalidad de los jóvenes, el gusto por la creación libre y el sentido de servicio a la comunidad".

Por otra parte, encontramos el reconocimiento del Derecho Internacional, que hemos de tener en cuenta conforme al artículo 10.2 CE: 
- Declaración Universal de los Derechos Humanos (ONU, 1948), artículo1: "Todos los seres humanos nacen libres e iguales en dignidad y derechos"; artículo 5: "Nadie será sometido a torturas ni a penas o tratos crueles o degradantes"; artículo 27.2: "Toda persona tiene derecho a la protección de sus intereses morales y materiales....".

-Convenio para la protección de los Derechos Humanos y de las Libertades fundamentales (Roma, 1950), artículo 10: "Toda persona tiene derecho a la libertad de expresión... el ejercicio de este derecho podrá ser sometido a ciertas restricciones que constituyan medidas necesarias en una sociedad democrática... para la protección de la moral la protección de la reputación o de los derechos ajenos, para impedir la divulgación de informaciones confidenciales...".

Finalmente, en el ámbito de la Unión Europea, en la Carta de los derechos fundamentales, alude a la integridad de la persona en su artículo II 63, y en el artículo II 64, a la dignidad de la persona.

El artículo II 84 reconoce la protección de los derechos del niño: "Los niños tienen derecho a la protección y cuidados necesarios para su bienestar......El interés superior del niño constituirá una prioridad".

Artículo II 92 .Protección de los jóvenes en el trabajo "Los jóvenes admitidos a trabajar dispondrán de condiciones de trabajo adaptadas a su edad....y contra cualquier trabajo que pueda ser perjudicial para su salud, su desarrollo físico, psíquico, moral o social o que ponga en peligro su educación.”

De todos ellos se desprende una enfática obligación de proteger a la juventud e infancia, reconociéndose su derecho al libre desarrollo de su personalidad, intrínsecamente ligado a su integridad moral, porque cuando se afecta cualquiera de los derechos de la personalidad, se produce un daño a la integridad moral, como afirma Alegre Martínez ${ }^{43}$ por eso en el reconocimiento y la protección constitucional de una una y otra, aparecen siempre unidas como exigencias imprescindibles que acompañan la constitucionalización de los derechos de la personalidad.

\section{Las TIC y la Dignidad e integridad de la juventud y adolescencia}

Un alto porcentaje de los menores no ha recibido información alguna sobre las normas básicas de seguridad a la hora de la utilización de dispositivos ciberespaciales, lo que refleja la importante falta de cultura informática, que puede provocar situaciones de riesgo ya que por esta falta de información, pueden derivarse nefastas consecuencias para los e-usuarios menores, irreversibles, ya que, aunque es una generación inmersa en la tecnología de la información, sin embargo, la vertiginosa rapidez de su desarrollo, ha impedido transmitir algo esencial, como que la vida real y la virtual, como afirma Pardo Albiach, deben regirse por los mismos códigos de conducta, y que el anonimato que muchas veces ampara a la red, no puede instrumentalizarse para dañar el derecho al honor, intimidad y propia imagen.

La tecnología de la información y comunicación (TIC), ha transformado la vida de la sociedad, convirtiéndose en verdaderos agentes de penetración y alfabetización tecnológica en los hogares, ahora bien la parte negativa de este proceso, es que ha

43 Alegre Martínez, M.A. (1996): La dignidad de la persona como fundamento del orden constitucional español, Ediciones Universidad de León. PARdo Albiach. J.: "Ciberacoso, ciberbullying, Grooming, redes sociales" en GARCÍA GONZÁLEZ (coord.), Ciberacoso: La tutela penal de la intimidad, la integridad y la libertad sexual en Internet, Tirant lo Blanch, Valencia, pág. 72. 
proyectado una "cultura de la habitación", como señala Marco Marco ${ }^{44}$ que retiene a los menores por horas, rodeados de recursos tecnológicos y aislados de la familia. Este aislamiento, sin ser necesariamente causa y efecto, sí que desde luego propicia que el menor pueda ser protagonista de algún episodio de ciberbullying, en consecuencia de posible vulneración de sus derechos fundamentales: dignidad, integridad moral, honor, intimidad y propia imagen.

Ocupa un lugar común en la doctrina, que si bien el daño moral no se define propiamente en el Código civil, como afirma Colás Escandón ${ }^{45}$, cabe entender que la referencia del artículo 1902 a "reparar el daño causado", cabe entenderla como el daño moral representado por el impacto físico o espiritual causado.

La jurisprudencia del Tribunal Supremo ${ }^{46}$, entiende por éste aquéllas manifestaciones psicológicas que sufre el perjudicado por el acaecimiento de ciertas conductas que por su naturaleza, no son traducibles en la esfera económica.

La integridad moral recogida en el artículo $15 \mathrm{CE}$, que conforme al artículo 10.2 CE debe ser interpretado con acuerdo a los Tratados y Convenios ratificados por España, adquiere la naturaleza de derecho absoluto e ilimitado, pues aunque la jurisprudencia constitucional ha establecido que "no existen Derechos ilimitados. Todo derecho tiene su límite" ${ }^{47}$, convenimos con un sector de la doctrina (García Cuadrado, Alegre Martínez ${ }^{48}$ ) que existen derechos que se consideran como absolutos, en cuanto que "la dignidad humana no puede consentir que la ley ampare el sacrificio, ni siquiera parcialmente, de tal derecho, como fundamento que es del orden político y de la paz social". De igual manera que, como mantengo en otro trabajo ${ }^{49}$, "el contenido mínimo esencial de este derecho, no es evaluable", como tampoco lo es el derecho a la vida o el derecho al honor, sino que o se respeta o no se respeta, ya que viene definido y reconocido con carácter de prohibición en la Constitución "en ningún caso". El TC, en la citada sentencia 2/1982, de 29 enero, niega que el ejercicio de un derecho fundamental haya de pasar por encima de otros bienes constitucionalmente protegidos como la dignidad humana y su derecho a la integridad moral y aunque el alto tribunal reconoce que la delimitación de esferas puede ser de difícil concreción, en el ámbito que nos ocupa como objeto de estudio en la esfera de la libertad de expresión a través de las TIC, entendemos que la libertad de expresión en el caso de las TICS puestas al servicio de invadir el espacio reservado a los derechos de la personalidad de menores, no gozan de cobertura constitucional, erigiéndose la integridad moral y la dignidad del menor como límite del ejercicio de aquélla libertad.

\section{Las TIC y los Derechos de la personalidad.}

Reconocida la dignidad e integridad moral como fundamento del orden político y punto basilar para el reconocimiento de los demás derechos, cualquier eventual

44 Marco Marco, J. (2010), "Menores, ciberacoso y derechos de la personalidad", en García GONZÁLEZ (coord.), Ciberacoso: La tutela penal de la intimidad, la integridad y la libertad sexual en Internet, Tirant lo Blanch, Valencia, pág. 85.

45 Colás Escandón, A. (2015), Acoso y ciberacoso escolar, La doble responsabilidad civil y penal, Wolters Kluver, Barcelona, pág. 404.

46 STS $139 / 2001$, de 22 de febrero, Sala $1^{\text {a }}$.

${ }^{47}$ STC 2/1982, de 29 de enero FJ 5.

48 García CuAdrado, A. (2003): Sistema constitucional de derechos y libertades, Alicante Editorial Club Universitario, pág. 19. Alegre Martínez, M. A. (1996): La dignidad de la persona como fundamento del orden constitucional español, Ediciones Universidad de León, pág. 7.

49 García-Atance García de Mora, M. V. (2003): "Derecho a la integridad física y moral", en Derecho Constitucional III. Derechos y Libertades, Madrid, Colex - UNED, págs. 140-148.

(C) UNED. Revista de Derecho Politico

N. 100 , septiembre-diciembre 2017, págs. 1271-1308 
vulneración de los derechos del artículo $18 \mathrm{CE}$, implicaría una conculcación de la dignidad como base del sistema de derechos y en íntima conexión con la integridad moral de la persona que opera como complemento ineludible en cuanto que garantiza la plena inviolabilidad del ser humano, en este caso del menor.

Estos derechos reconocidos en el artículo 18 tienen una serie de rasgos comunes y aunque tienen un tronco común son independientes, distintos y autónomos, como señala Rebollo Delgado ${ }^{50}$ y constituyen bienes jurídicamente protegidos, quedando sujetos a la tutela de los tribunales ordinarios en procedimiento preferente y sumario (Artículo 53.2 CE). Estos derechos de la personalidad son particularmente frágiles ante determinadas prácticas en el ámbito de la actividad de las Tic, que pueden vulnerar fácilmente el honor, la intimidad y propia imagen de los menores, con el agravante de la reiteración en el tiempo por verificarse en la red.

La Comisión Europea, consciente del riesgo de los derechos de los adolescentes en estas redes abiertas, elaboró un Libro verde ${ }^{51}$ sobre la protección de los menores y la dignidad humana, en el que subraya la importancia de la Recomendación del Consejo relativa a la promoción de marcos nacionales, destinados a lograr un nivel de protección efectiva de los menores y de la dignidad debida.

Por otra parte, en los sistemas abiertos cuyo paradigma es Internet, en el que resulta difícil establecer una cadena de responsabilidad, ya que los receptores son también difusores, la propia industria ha desarrollado ciertas soluciones técnicas como: restricción en el uso del ordenador, limitación en las facilidades de navegación, filtros sistemáticos del material, códigos, bloqueos de lugares, etc., manifestando con ello un relevante interés de protección de los menores frente a las posibles incursiones ilícitas contra los derechos de la personalidad de de éstos, y que proyecta, dotando de mecanismos de protección reforzado a los derechos al honor, intimidad y propia imagen, en la línea mantenida por Desantes Guanter ${ }^{52} \mathrm{de}$ régimen especial de protección de los menores conforme a unos deberes deontológicos.

\subsection{Redes sociales y derecho al honor}

El honor configura un bien patrimonio de la persona y del concepto que se tiene de uno mismo. Este es un concepto relacionable con las ideas y valores preponderantes en cada momento histórico, y que responden a una idea fluida, inconcreta e indeterminada, como señala Chinchilla $^{53}$, aunque puede invocarse una aproximación que caracteriza este concepto en base a dos ámbitos que han sido aportados por la jurisprudencia del TC:

-La íntima conexión entre el derecho al honor y la dignidad de la persona (SSTC 105/1990 de 6 Junio y 214/1991 de 11 Noviembre).

-Su carácter eminentemente personalísimo, como derecho de las personas individualmente consideradas, relacionándose este derecho con conceptos como prestigio, fama, reputación y dignidad personal, ámbitos éstos que pueden muy fácilmente ser vulnerados como hemos tenido ocasión de ver en epígrafes anteriores a

${ }^{50}$ Rebollo Delgado, L. (2003), "Derecho al Honor. Derecho a la intimidad y a la propia imagen”, en García-Atance García de Mora, M. V., Derecho Constitucional III. Derechos y Libertades, Madrid, Colex - UNED, pág. 177.

51 98/560/CE. Disponible en: http:/ / eur-lex.europa.eu/legal-content/ES/ALL/?uri=uriserv:124030

52 Desantes Guanter, J. M. (1978), "Fundamentación jurídica del tratamiento especial de la información infantil y juvenil" en el volumen colectivo Teoria y práctica de las publicaciones infantiles y juveniles, Ministerio de Cultura, pág. 79.

53 ChinChilla Marín, C. (1995), "El derecho al honor en la jurisprudencia del TC", en Cuadernos de derecho judicial. Honor, intimidad y propia imagen, Ministerio de Justicia e Interior, Madrid, pág. 107.

(C) UNED. Revista de Derecho Politico 
través del uso indebido de las tic en episodios de ciberbullying y otros, perjudicando gravemente el desarrollo integral del menor.

\subsection{Redes sociales: Derecho a la intimidad}

Aunque el concepto de intimidad no es aclarado en nuestra Constitución, ni tampoco lo es en la Ley 1/ 82, sin embargo, un sector de la doctrina civil representado por Albadalejo ${ }^{54}$ entiende por ésta: "El poder concedido a la persona sobre el conjunto que forman su círculo íntimo personal y familiar y que le permite excluir a los extraños de entrometerse en él y darle una publicidad que no desee el interesado". Esto mismo se proyecta al control de uno mismo sobre todas las informaciones relativas a la persona sobre datos personales, flujo de información, etc., por encontrarse en el ámbito más inmediatamente cercano a la persona y en intensa relación con la dignidad de ésta.

Así, la intimidad se relaciona con la esfera más reservada que se preserva de miradas ajenas y de la información que pueda circular en el escenario público a través de las TIC, en línea marcada por el TC ${ }^{55}$ al reconocer la intimidad como "Un núcleo inaccesible predicable de todas las personas, incluso las más expuestas al público". De conformidad con el artículo 7 de la Ley Orgánica de 1/82, hay tres intromisiones ilegítimas que pueden invocarse en relación con el tema de riesgo de adolescentes y menores en las redes relacionadas con el ciberespacio:

a) La intromisión en la vida íntima de las personas mediante emplazamiento en cualquier lugar con la utilización de aparatos de filmación, escucha o cualquier otro dispositivo óptico o análogo dirigido a conocer la vida de las personas.

b) La publicación divulgación o revelación, dando a conocer a terceros o al público en general, datos de la vida privada de una persona. En esta línea, como afirma Torres del Moral ${ }^{56}$, las personas - adultos o adolescentes - tienen derecho a decidir por sí mismas cuándo y dentro de qué límites procede revelar datos referentes a su propia vida.

En esta misma línea se pronuncia el Tribunal Constitucional Alemán ${ }^{57}$, que reconoce la libertad personal como autodeterminación individual, la cual incluye la autodeterminación informativa, en la misma línea preconizada por Lucas Murillo ${ }^{58}$, como garantía de los derechos de la personalidad, frente a la injerencia que pueden suponer las TIC en estos derechos.

c) El quebrantamiento de un secreto por parte de un profesional.

En todo caso, hay que tener presente que la eventual veracidad de los datos que se hagan públicos, no exonerarían de responsabilidad por vulnerar la intimidad de la persona. Así, resulta lógico que desde diversos ámbitos sociales se reclame una mayor protección de la intimidad, frente a los riesgos que encierran las redes sociales e Internet, puesto que, el concepto de intimidad, ha ido mudando su contenido ante la nueva realidad del desarrollo tecnológico, como afirma Morales Prats" ${ }^{59}$ ya que "En el

\footnotetext{
54 Albaladejo García, M. (2013), Derecho Civil I. Introducción y Parte General. Edisofer S.L., 19. edic. Madrid.

55 STC 134/ 99, de 15 Julio.

56 TORRes Del Moral, A. (2010): Principios de derecho Constitucional Español, vol.1, $\sigma^{a}$ edición renovada. Servicio de Publicaciones Facultad Derecho.Universidad Complutense, Madrid.

${ }^{57}$ STCFA de 15 -XII-1983 sobre ley del censo; cfr. Sentencia caso FLICK.

${ }^{58}$ LuCAS Murillo, P. (1990), El derecho a la autodeterminación informativa. Madrid.

${ }^{59}$ Morales Prats, F. (1995): "La protección penal de la intimidad frente al uso ilícito de la informática en el código penal de 1995”, en Cuadernos del Poder Judicial, 3:147-196.
} 
nuevo escenario, la intimidad también evoluciona, pasando a incluir un derecho de control sobre los datos personales que circulan en la sociedad tecnológica", lo que significa que de este bien jurídico, no sólo derivan facultades de exclusión de terceros, sino también facultades positivas de control sobre los datos personales, pudiéndose, por tanto, ejercitar facultades jurídicas en los circuitos informático, dando pie al habeas data, con todo el entramado jurídico e institucional que conlleva :agencia de protección de datos, derechos de control sobre esos datos, etc...

El desarrollo de las redes sociales ha dejado pequeño el concepto intimidad, ya que, a pesar de todo el entramado social diseñado para garantizar esa protección, existe una ingente cantidad de datos personales en las redes sociales fuera de control y que son monitorizados con y sin conocimiento de los titulares; por lo que afirma García González $^{60}$, los conceptos tradicionales asociados a la intimidad informativa, resultan insuficientes. Esto provoca una aún mayor desprotección adicional en relación al menor, que vuelca de forma, más o menos, inconsciente todo su perfil en las redes porque ¿Cómo proteger a quien voluntariamente desvela su actividad informática, bien sea por ignorancia de la relevancia y consecuencias de sus actos, o por simple deseo de notoriedad, y que ya es incapaz de evitar su monitorización a través de estos medios?

Difícil dar respuesta, en este caso, el acceso de las personas a tales datos facilitados voluntariamente por el menor, será lícito, y no justificaría la apelación a la protección del menor una vez arrepentido de tal cesión, ya que al haber cedido el menor voluntariamente sus datos de privacidad, el problema es si se puede o no, proteger la intimidad del menor, frente a su propia voluntad y que, en consecuencia,tales datos cedidos voluntariamente, circulan libremente por las redes, y en tal sentido, el legislador establece como límite la "intromisión ilegítima" en el derecho a la intimidad, supuesto que no se da en este caso al haber mediado voluntad del menor.

\subsection{Redes sociales: Derecho a la propia imagen.}

Por derecho a la propia imagen entendemos la facultad del interesado de difundir o publicar su propia imagen, así como, en sentido contrario, su derecho a evitar su reproducción, al tratarse de un derecho de la personalidad y por tanto sujeto al grado máximo de garantías constitucionales contempladas en el artículo $53 \mathrm{CE}$. En este derecho sucede lo mismo que con los demás derechos de la personalidad relacionados con la dignidad de la persona, que no puede limitarse lo que es ilimitado tal como entiende el Tribunal Constitucional ${ }^{61}$, como vimos con anterioridad.

La razón que justifica la autonomía y diferenciación de este derecho respecto a los demás derechos de la personalidad radica en que es un instrumento básico de proyección exterior del individuo $^{62}$ y que supone la reproducción de los rasgos físicos de la persona sobre cualquier soporte material, incluidos, muy particularmente para nuestro objeto de estudio, los distintos dispositivos usualmente empleados por las TIC.

Ahora bien, en el caso del derecho a la imagen, la eventual lesión del derecho a controlar la difusión de ésta, se presumirá, conforme determina el artículo 9.3 de la Ley Orgánica 1/82, "Siempre que se acredite la intromisión ilegítima", es decir, lo relevante

\footnotetext{
${ }^{60}$ García GonzÁlez, J. "Protección penal de la intimidad: el art.197. 1º del Código Penal”, en García GONZÁLEZ (coord.), Ciberacoso: La tutela penal de la intimidad, la integridad y la libertad sexual en Internet, Tirant lo Blanch, Valencia.

${ }^{61}$ STC 2/1982, de 29 de enero.

${ }^{62}$ LuCAs Murillo, P. (1993): Informática y protección de datos, CCC, Madrid.
} 
es en este supuesto, no es, como sostiene Rebollo Delgado ${ }^{63}$, tanto el daño, sino que lo esencial es la constatación o no de una intromisión no consentida en el ámbito de la vida privada. Es particularmente invocable la vulneración de este derecho de la personalidad, para el caso de la técnica de morphing, utilizando la originaria imagen del menor víctima, para hacer burla de él a través de la sucesiva transformación de la imagen hasta dar origen a una imagen esperpéntica (vide II-7).

\section{VICTIMIZACIÓN DE MENORES EN EL ÁMBITO DE LAS NUEVAS TECNOLOGÍAS.}

El problema del daño al menor proveniente del irresponsable uso de las TIC, es una realidad social que puede llegar a comportar graves consecuencias en el desarrollo de la personalidad " in fieri " del menor, que por razón de edad no es lo suficiente consciente de los peligros del riesgo social, emocional y psicológico que tales prácticas pueden provocar, si no se realizan con la cautela adecuada y que puede provocar una victimización de los menores comportando,en ocasiones, consecuencias en el desarrollo de su personalidad., particularmente, cuando se convierten en sujetos pasivos de acoso a través del ciberespacio, tanto en manifestaciones de ciberbullying, como de grooming, y cualquier otra que se efectúe a través de las TIC.

A pesar de sus nefastas consecuencias, la victimización derivada del mal uso de las TIC, no ha sido estudiado hasta fechas recientes y a pesar de la sensibilidad mostrada internacionalmente para proteger a la juventud e infancia de las consecuencias de navegar sin cautela en la red, a través de del desarrollo de normas y Convenios como la Convención de los derechos de los niños de las Naciones Unidas de 1989 ratificad por España en 1990; el Convenio e protección del niño y la cooperación en materia de adopción internacional de La Haya de 29 de Mayo 1993, el Protocolo facultativo de la Convención de derechos del niño de venta, prostitución infantil y utilización de niños para pornografía (Nueva York 25 Mayo 2000), la Directiva de la televisión sin fronteras, de 5 de Mayo 1989, la Recomendación número 1121 de la Asamblea parlamentaria del Consejo de Europa, relativa a los derechos de los niños de 24 de enero 1996, la Resolución del Parlamento Europeo sobre medidas de protección de menores en la Unión Europea A.4-0393/96, la Resolución A-40227/97 de 24 Octubre 1997 sobre Libro Verde relativo a la protección de menores y a la dignidad humana, en los nuevos servicios audiovisuales e información.

A pesar de esta normativa, la infancia se encuentra en situación de riesgo ante las TIC. En este contexto, el concepto de victimología del desarrollo juvenil entiende que la infancia sufre la misma victimización que los adultos, pero en peor situación, por experimentar a su vez la vivencia, ya sea directa o indirecta de otras muchas victimizaciones vinculadas a su nivel de dependencia, lo que les confiere mayor grado de vulnerabilidad y victimización tal como afirma Pereda, Abad y Guilera ${ }^{64}$.

Pero además de su posición vulnerable frente a los ilícitos derivados de Internet, hay que añadir la victimización adicional - doble victimización - por las

\footnotetext{
${ }^{63}$ Rebollo Delgado, L. (2003), "Derecho al Honor. Derecho a la intimidad y a la propia imagen", en García-Atance García de Mora, M. V. (coord.), Derecho Constitucional III. Derechos y Libertades. Colex, Madrid, pág. 187.

${ }^{64}$ Pereda, N., ABAd J., Gullera, G. (2012), "Victimización de menores a través de Internet", DíAZ Cortés, L. M.; PÉrez Álvarez, F. (ed. lit.), Delito, pena, política criminal y tecnologías de la Información y de la Comunicación en las Ciencias Penales. II Congreso Internacional de jóvenes investigadores en Ciencias Penales, Salamanca, pág. 92.
}

(C) UNED. Revista de Derecho Politico

N. 100 , septiembre-diciembre 2017, págs. 1271-1308 
consecuencias psicológicas y sociales que de ello pueden derivarse, llegando a provocar incluso graves casos de polivictimización, o acumulación de diversos casos de victimización en adolescentes.

La tecnología en general, es un agente importante para el desarrollo de habilidades cognitivas y de socialización de la juventud actual a través del fácil acceso a una amplia variedad de tecnologiías de la información, como señala Willoughby ${ }^{65}$ y las TIC. El uso de las nuevas tecnologías y los distintos dispositivos para su aplicación es un escenario nuevo y excitante donde relacionarse y explorar mundo, siendo incluso raro que en la actualidad haya adolescentes que no tengan acceso a un ordenador, frecuentemente situado en su propia habitación, y que lo utilicen habitualmente tanto en un ámbito educativo, como social, pero esto no exime de los potenciales peligros que implica el mal uso de estos recursos.

En este contexto hay que señalar que un $7 \%$ de menores manifiesta no apreciar ningún factor de riesgo en que un desconocido tenga acceso a la información de datos sobre sus aficiones o vida personal; por su parte, un $13 \%$ manifiesta no tener inconveniente en agregar desconocidos a sus contactos virtuales y un $12 \%$ encuentra divertido hablar con desconocidos por las redes e Internet.

Tiene especial interés en este sentido, un estudio realizado para el Defensor del Menor por parte de la Asociación ACPI - Acción contra la Pornografía Infantil y Protégeles - "Seguridad infantil y costumbres de los menores en Internet" ${ }^{66}$, que pone de relieve los riesgos de los menores españoles que se citan en el mundo real con alguien que sólo conocen virtualmente.

Este escenario es un terreno especialmente óptimo para una potencial victimización de menores a través de las TIC, convirtiéndose en un problema de interés jurídico-social por la alarma que se ha generado en la sociedad debido a la facilidad con la que por Internet pueden cometerse gran número de ilícitos vinculados a la indemnidad de los menores, debido a la libertad y medio anónimo con la que los delincuentes cibernéticos cuentan,la facilidad de los menores para acceder a Internet y la especial vulnerabilidad de este os menores, por lo que se ha planteado ${ }^{67}$ la necesidad de incorporar tipos penales que protejan la libertad del menor.

El perjuicio del menor, esto es la victimización de la que se hace objeto al menor adolescente en los ilícitos derivados de las TIC, es doble, e incluso se puede hablar de polivictimización, como señalamos anteriormente, porque el medio empleado en las redes sociales - caso tuenti- para vejar y hostigar a un menor, es reiterativo ya que permite la permanente difusión del perverso contenido ofensivo al menor o imagen del mensaje, provocando una victimización plural, ya que aunque la acción ilícita fuera solo una, sus efectos permanecen con la progresiva difusión de

${ }^{65}$ WilloughBY T. (2008): “A short -term longitudinal study of internet and computer game use by adolescente boys and girls: Prevalence, frequency of use and psychosocial predictors”, en Developmental psychology; 44-2008 pág. 195.

66 ACPI: Seguridad infantil y costumbres de los menores en internet (2002). http://www.protegeles.com/docs/estudio_internet.pdf

${ }_{67}$ Sobre este punto Edit Bauer, en nombre del PPE-DE en el Parlamento Europeo, en debate sobre la propuesta de recomendación del Parlamento Europeo destinada al Consejo sobre la lucha contra la explotación sexual de los niños y la pornografía infantil presentada por Roberto Angellili, señala: "el informe de Europol de 2006 sobre delincuencia organizada informaba que las ventajas que Internet ofrece en términos de información y tecnología de la comunicación, son extremadamente beneficiosas para la delincuencia de organizada. Al respecto, no cabe duda alguna de que los niños son los más vulnerables. Según los expertos, cerca del 90\% de los menores entre 12 y 17 años chatea en Internet”.

(C) UNED. Revista de Derecho Político 
aquéllas y con ellas, el sufrimiento de la víctima, como afirma Miró Llinares, ${ }^{68}$ y la afectación de la dignidad e integridad moral del menor.

\section{CONCLUSIONES}

En la actualidad el concepto de Moral se vincula a la idea de conducta de lo que debe hacerse. Este código de conducta moral, parte esencial de la sociedad, es muy variable y por tanto, posiblemente puede evolucionar, conforme muda el sentimiento social e individual. Pero de lo que nunca puede desviarse es de la libertad y la razón conforme a la voluntad libre de elegir y la capacidad de discernimiento, imprescindibles para la calificación de una conducta como moral e inmoral, en la pretensión de un canon social de corrección y correspondiente rechazo, en caso de desviación.

Este posicionamiento de conductas se proyecta en diversas áreas de la vida: en las relaciones sociales, bioética, tolerancia, libertad, uso de las tecnologías, sexo, libertad, mentira. En definitiva, el concepto de moral gira en sus inter-relaciones configurando canon de comportamiento que nutre la conciencia social pero que necesita del derecho, de la juridicidad, para dar respuesta a todas las exigencias morales que demanda la sociedad.

Desde esta posición se precisa una vertebración jurídica de la eticidad, o moral dominante de la sociedad, por configurar ésta un concepto supraordenado al derecho, como afirma Barroso Asenjo ${ }^{69}$.

El Tribunal Constitucional, por su parte, ha tenido ocasión de pronunciarse $\mathrm{e}^{70}$ sobre el concepto de la dignidad y el derecho a la integridad moral, constitucionalmente protegible (artículos 10 y $15 \mathrm{CE}$ ), las cuales se vulneran con las manifestaciones de acoso al menor en las TIC, y aunque la delimitación de la misma sea, en ocasiones, de difícil concreción, no sería el supuesto de los bienes vulnerados en las agresiones que se acometen contra el menor a través de las TIC, reconociendo que el concepto de moral puede ser utilizado por el legislador y aplicado por los tribunales, invocando su legitimación como bien protegible en la legislación tanto de ámbito nacional (CE), como internacional (Declaración Universal de Derechos Humanos 1948, Pacto Internacional de Derechos civiles y Políticos de Nueva York 1966 y Convenio para la Protección de Derechos Humanos y Libertades fundamentales 1950), si bien, rodeándose el concepto de moral de todas las garantías para que bajo un concepto ético juridificado, no se produzca una limitación injustificada de un derecho fundamental.

Por su parte el Convenio Europeo (artículo 10) eleva la protección de la moral a tal rango, que justifica la existencia de límites incluso a derechos fundamentales "Con tal de que con ello se adopten medidas necesarias en una sociedad democrática para... la protección de la moral ... la protección de la reputación los derechos ajenos, para impedir la divulgación reinformaciones confidenciales", reconociéndose así el concepto de moral. Reconoce así el alto Tribunal el concepto de moral incluyendo asi

\footnotetext{
${ }^{68}$ Miró Linares, F. (2013): "Derecho Penal, Ciberbullying y otras formas de acoso no sexual en el ciberespacio", en Revista d 'Internet, dret i Politica IDP n 16 junio 2013, pág. 66.

${ }^{69}$ Barroso Asenjo, P. (1984): Limites constitucionales al derecho de información. Editorial Mitre. Barcelona, pág. 12.

${ }_{70}$ STC 2/ 1982, de 29 Enero, Fundamento 5; STC 62/1982, de 15 Octubre, Fundamento 2 y 3
}

(C) UNED. Revista de Derecho Politico

N. 100 , septiembre-diciembre 2017, págs. 1271-1308 
mismo la protección de la juventud e infancia como bien constitucionalmente protegible $^{71}$.

Hay que subrayar el especial interés en la protección de la moral tanto en la normativa nacional y europea así como en la internacional lo que ha influido en la sensibilidad del legislador orgánico para que tanto en la Ley Orgánica de Protección jurídica del menor de 15 de Enero 1996, así como la Ley Orgánica 8/ 2015 de 22 de Julio de Modificación de la Ley Orgánica de Protección del menor, hayan hecho prevalecer el interés superior del menor, incorporando tanto la jurisprudencia del Tribunal Supremo, como los criterios de la Observación general $\mathrm{N}^{\mathrm{o}} 14$ de 29 Mayo de 2013, del Comité de Naciones Unidas del derecho del Niño,en la línea de que este derecho sea una consideración primordial, de forma que el interés superior del menor se proyecte en asegurar el respeto completo y efectivo de sus derechos respecto a su desarrollo integral atendiendo a criterios generales de ponderación tales como: su edad y madurez, la necesidad de garantizar su igualdad y no discriminación, particularmente, por su especial vulnerabilidad, entre otras circunstancias.

En realidad podría sincretizarse en un único sistema de hostigamiento al menor a través de las TIC, que se cifra en el acoso entendido de manera genérica, siendo el bien o bienes jurídicos lesionados los que definirían el tipo de agresión en la que el hostigamiento al menor, se manifiesta, tales como: ataque a su integridad moral, daño a su propia imagen, lesión de su honor, así como de su libertad, en el supuesto de amenazas o coacciones.

A pesar de una ausencia de tipificación expresa de los ilícitos a través del espacio, el código penal, a través de los distintos tipos penales que regulan intereses de los menores, tales como su dignidad, intimidad, honor, imagen, etc., responde adecuadamente a estas agresiones cometidas por la red.

Las vías de agresión y acoso al menor por las TIC en las distintas modalidades vistas, configuran una vulneración frontal del menor en su dignidad e integridad moral como derecho absoluto e ilimitado, conforme a la naturaleza de estos dos conceptos que, como tiene reconocido un sector de la doctrina, no son evaluables. Hay ataque a la dignidad e integridad del menor, o no la hay, pero en términos absolutos. Y, de otra parte, casi todos los instrumentos de abuso a menores por el ciberespacio, tienen un común denominador, provocar un profundo dolor psíquico -emocional e imposibilidad de defensión.

Frente a la frecuente impunidad de las diversas manifestaciones en las redes y en el ciberespacio al menor, no cabe sino la aplicación de un sistema adecuado de transversalidad que giraría en torno a un trípode configurado por prevención, detección e intervención.

Estos planes transversales parten de los diferentes ámbitos en los que el menor desarrolla habitualmente su vida: familiar, educativo y social; aunque todos son necesarios, es particularmente efectivo, el que concierne al ámbito educativo, puesto que es el centro escolar el lugar donde más habitualmente frecuenta el menor su relación social, sin perjuicio de sus contactos en el espacio.

En este orden, en los distintos niveles educativos debe presidir la transmisión de valores de respeto a la dignidad e igualdad, intentando eliminar por parte de los docentes, los obstáculos que dificultan la plena igualdad, así como la pacífica resolución de los conflictos entre los menores y trasladándolo conforme a la edad de aprendizaje, a lo largo de la educación primaria, secundaria y bachillerato.

A pesar de que la agresión al menor por las redes y ciberespacio se cometiera una sola vez, quien la verifica deja de ser dueño del ataque, insulto, amenaza,burla, etc,

${ }^{71}$ STC 62/1982 de 15 Octubre y 185/ 1980.

(C) UNED. Revista de Derecho Politico 
aunque siga siendo responsable, ya que la agresión queda libremente navegando por las redes y siguiendo afectando gravemente la integridad y dignidad del o la menor, dada la naturaleza del medio a través del cual se verifica el ciberataque. Hay que tener presente la posibilidad de que sus efectos se repitan en el tiempo mientras sigan navegando por el ciberespacio, lo que comporta el efecto perjudicial sobre el menor su victimización - se multiplique, provocando una doble victimización o incluso una polivictimización.

Title:

Diverse evidence of social and moral risk in minors in an information and communication environment.

\section{Summary:}

INTRODUCTION. I. PRINCIPLES OF PREVALENCE OF THE BEST INTEREST OF THE MINOR IN SOCIAL NETWORKS. II. A REFLECTION ON THE INADEQUACYOF THE LEGALMECHANISMS AROUND THE PROTECTION OF MINORS IN THE FIELD OF SOCIAL NETWORKS. III. PREVENTIVE MEASURES AGAINST THE RISK OF MINORS IN ICT AND INTERNET. 1. Obtaining consent. 2. Verification of the minor's age. 2.1. Limitation of minimum age of participation in social networks. 3. Information trail of Minors in social networks. 4. Brief reflection on the protection of minors' data in the network. 4.1. Applicable legislation. 4.1.a) Scope of the organization that uses the data. 4.1.b) Location of the subjects whose data have been used. 4.1.c) Location of the actual processing of the data. 5. Projection of risks on the rights of the minor's personality: Unitary regulation of the EU. 6. Influence of the network in educational centers: Its emotional impact on minors. IV. COEXISTENCE PLAN IN EDUCATIONAL CENTRES. V. CONCEPTUAL APPROXIMATION IN DIVERSE SCENARIOS WHERE MINORS ARE AT SOCIAL RISK. 1. Minors exposed to episodes of social and physical harassment. 2. Minors' vulnerability to cyberbullying. Emotional risk factor. 2.1. Concept. 2.2. Contents. 2.3. Cyberbullies' motivations. 3. Minor's marginalization as a consequence of Bullying. Physical risk factor. 3.1. Concept of Bullying. 3.2. Contents of Bullying. 3.3. Bullying goals. 4. Cyberbullying as a specific type of harassment. 4.1. Concept of Cyberbullying. 4.2. Contents of Ciberbullying. 4.3. Evidence of Cyberbullying. 5. Evidence of social and moral risk of minors. Grooming as evidence of harassment. 5.1. Aim of Grooming. 5.2. Psychological impact of Grooming in minor. 6. Sexting as a technological risk factor. 7. Morphing (Warping). VI. CROSS-SECTIONAL PROGRAM FOR SITUATIONS OF SOCIAL AND MORAL RISK OF MINOR. 1. Prevention methods for risk factor. 2. Means for prevention. 3. Intervention. VII. MINOR'S PERSONALITY RIGHTS AND TECHNIQUES OF INFORMATION AND COMMUNICATION AS TRANSGRESOR ELEMENTS OF MINOR'S DIGNITY. 1. Framework for minor's dignity and integrity. 2. Information and Communication techniques and the dignity and integrity of minor. 3. Information and Communication techniques and integrity in minor's youth and adolescence. 2.1. Social networks and honor rights. 2.2. Social networks and the right for intimacy. 2.3. Social networks and image rights. VIII. DOUBLE VICTIMIZATION OF MINOR. CONCLUSIONS

\section{Resumen:}

El progreso de la tecnología en los medios de la información y comunicación comporta una evolución social que se proyecta particularmente, en las últimas generaciones, nacidas en la era digital, lo que implica un salto cualitativo en la esfera de la globalización social, permitiendo una fácil accesibilidad de las personas, y de

(C) UNED. Revista de Derecho Politico 
los jóvenes en particular a distintos ámbitos sociales, hasta hace poco tiempo, impensables, a la vez que un elevado conocimiento de datos de privacidad de las personas que navegan por las redes, no siempre son tratados con la prudencia debida. Esta circunstancia, unida a la espiral de degradación del respeto a valores y principios, provocan con frecuencia episodios de uso perverso de las TIC, especialmente, aplicándolas en determinados ámbitos en los que la juventud e infancia son principales protagonistas y más vulnerables, con la intención de hacer daño, intimidar, amenazar, victimizar a los menores en el tiempo, puede conducir a resultados, a veces trágicos. La vulnerabilidad de los menores frente al desafío de las nuevas tecnologías, no siempre controladas a través de un adecuado uso por parte de los menores, hace urgente una más exhaustiva y precisa regulación en la UE, y mayor armonización de criterios en el ámbito de las regulaciones internas de cada Estado.

\section{Abstract:}

The progress of technology in the media of information and communication entails a social evolution that is particularly projected, in the last generations, born in the digital era, which implies a qualitative leap in the sphere of social globalization, allowing easy accessibility of people, and of young people in particular to different social areas, until recently, unthinkable, while a high knowledge of privacy data of people browsing the networks, are not always treated with the prudence due. This circumstance, together with the spiral of degradation of respect for values and principles, frequently provokes episodes of perverse use of ICT, especially applying them in certain areas in which youth and childhood are the main protagonists and more vulnerable, with the intention to harm, intimidate, threaten, victimize children over time, can lead to results, sometimes tragic. The vulnerability of children to the challenge of new technologies, not always controlled through proper use by the minors, makes urgent a more exhaustive and precise regulation in the EU, and greater harmonization of criteria in the scope of the internal regulations of each State.

\section{Palabras clave:}

Interés superior, consentimiento, edad, menores, acoso físico, ciberbullying, Grooming, sexting, morphing, prevención, intervención, dignidad, integridad, derechos de la personalidad, honor, intimidad, imagen, victimización.

\section{Key words}

Higher interest, consent, age, minor, physical harassement, cyberbullying, emotional risk, grooming, sexting, morphing, prevention, intervention, dignity, integrity, personality rights, honor, intimacy, image, victimization. 